
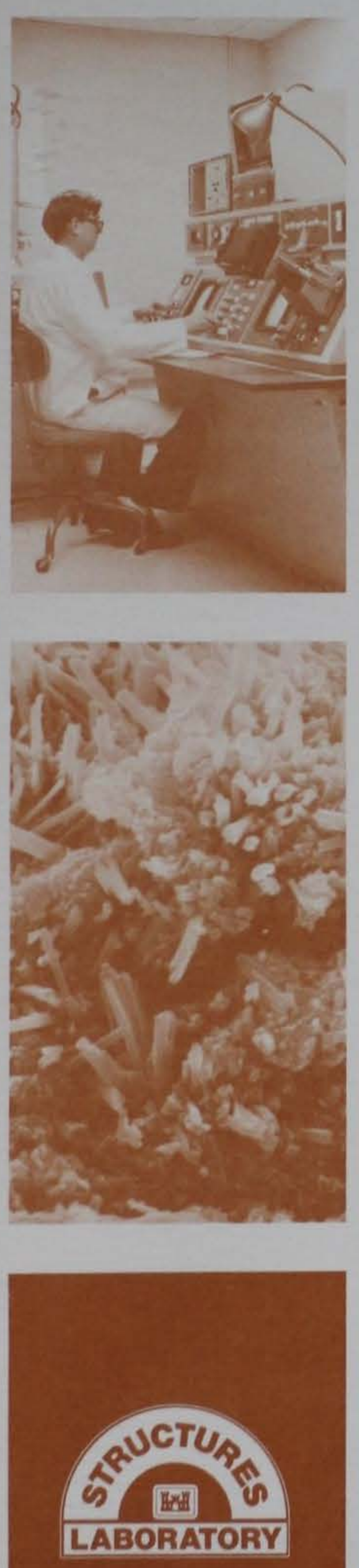

US-CE-CDroperty of the United States Government MISCELLANEOUS PAPER SL-83-6

\section{INVESTIGATION OF CEMENT PASTES AND RELATED MATERIALS BY SCANNING ELECTRON MICROSCOPY AND X-RAY DIFFRACTION}

by

Katharine Mather, Charles R. Hallford, J. Pete Burkes, and Alan D. Buck

Structures Laboratory

U. S. Army Engineer Waterways Experiment Station

P. O. Box 631, Vicksburg, Miss. 39180

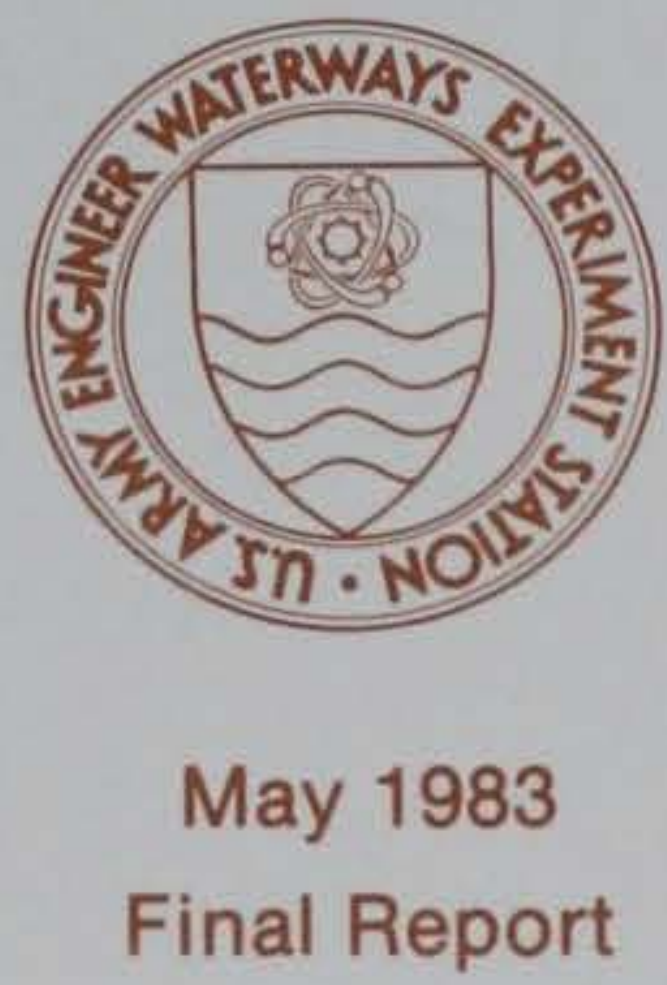

Approved for Public Release; Distribution Unlimited

LIBRARY BRANCH

TECHNICAL INFORMATION CENTER

US ARMY ENGINEER WATERWAYS EXPERIMENT STATION VICKSBURG, MISSISSIPPI

Prepared for Office, Chief of Engineers, U. S. Army Washington, D. C. 20314 
Unclassified

SECURITY CLASSIFICATION OF THIS PAGE (When Data Entered)

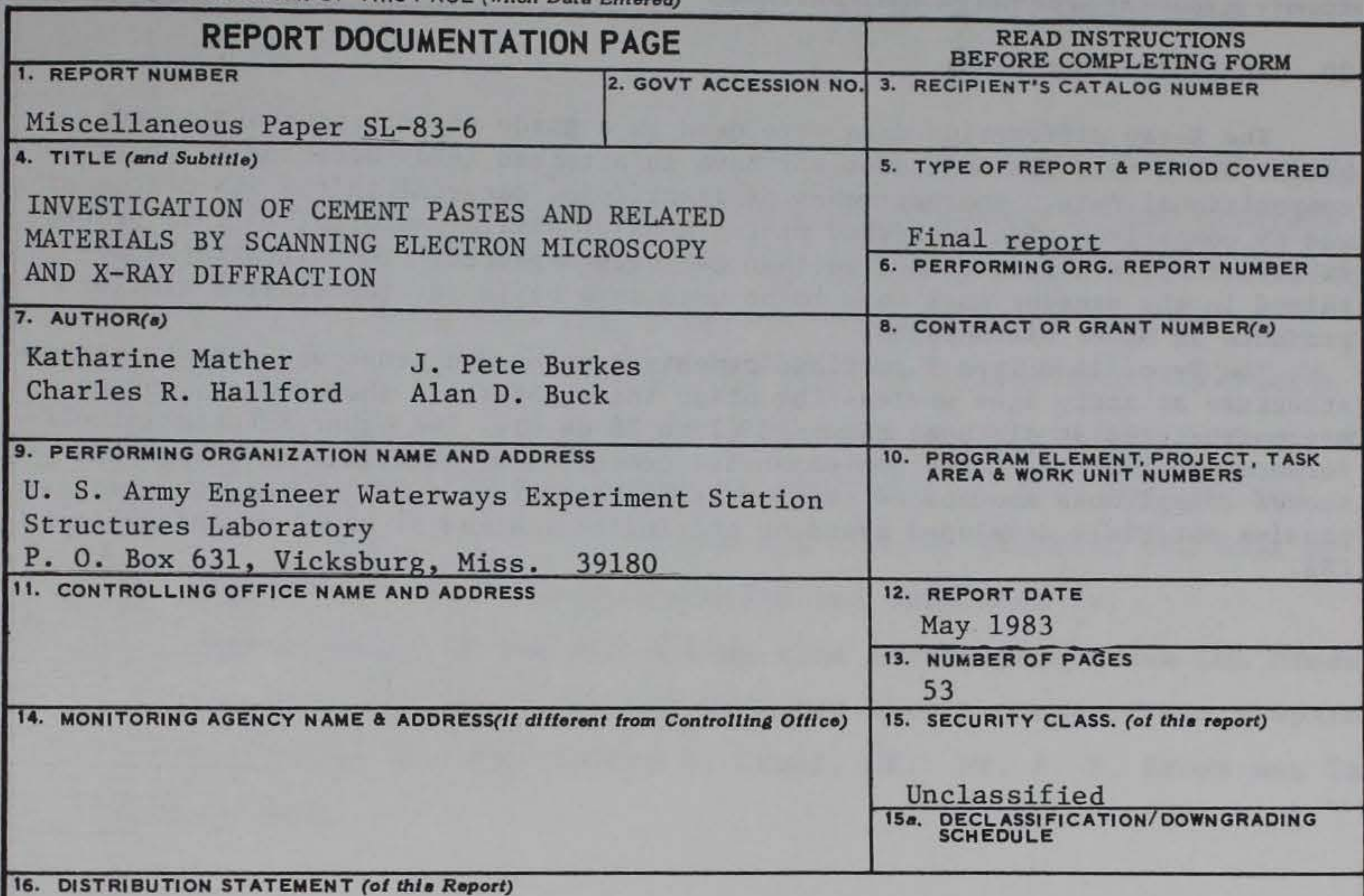

Approved for public release; distribution unlimited.

17. DISTRIBUTION STATEMENT (of the abstract ontered in Block 20, if different from Report)

18. SUPPLEMENTARY NOTES

This is CTIAC Report No. 4. Available from National Technical Information

Service, 5285 Port Royal Road, Springfield, Va. 22151.

\section{KEY WORDS (Continue on reverse side If necessary and identify by block number) \\ Cement pastes \\ Electron microscopy \\ Petrographic analysis \\ $\mathrm{X}$-ray analysis \\ $\mathrm{X}$-ray diffraction}

\section{2a. ABSTAACT (Continue an roveras stobs if necesesary and tdentify by block number)}

Five samples were examined after hydration by scanning electron microscopy (SEM) and both before and after hydration by X-ray diffraction to establish microstructural and compositional data. The majority of the work was done on hydrated material. These samples consisted of three non-expansive cementitious and two expansive cementitious materials. The three non-expansive cementitious materials were an alite, a Type I portland cement, and a Type V portland cement. The two expansive cementitious materials were an ettringite-forming material and a Type $\mathrm{K}$ expansive cement.

(Continued) 


\section{ABSTRACT (Continued).}

The X-ray diffraction data were used as a guide to interpret SEM micrographs since this SEM unit does not have an attached X-ray detector to provide compositional data. Another means of identifying material in the SEM micrographs was by comparison with published micrographs of similar materials. This proved satisfactory to a greater degree than had been expected. The micrographs obtained in the present work were to be used as a basis for identifying similar products in other micrographs.

The Type I and Type V portland cements developed a dense and compact microstructure at early ages whereas the other three materials showed open, porous microstructures at all ages examined ( 7 to 28 days). The other substantial difference was that the three non-expansive cementitious materials developed and showed conspicuous amounts of calcium silicate hydrate (CSH) whereas the two expansive materials developed abundant ettringite instead of abundant and evident $\mathrm{CSH}$. 
Funds for the publication of this state-of-the-art report were provided from those made available for the operation of the Concrete Technology Information Analysis Center (CTIAC). This report is CTIAC Report No. 4. The CTIAC supported the work which was done in the Petrography and X-ray portion of the Structures Laboratory (formerly Concrete Laboratory) of Waterways Experiment Station (WES) during part of FY 1972 and FY 1973 by Charles R. Hallford, J. Pete Burkes, and Katharine Mather. Mr. Hallford and Mrs. Mather prepared the bulk of this report. Mr. A. D. Buck assembled and completed it.

The Director of the WES during this investigation was COL Ernest D. Peixotto, CE. The Commander and Director when the report was prepared for publication was COL Tilford C. Creel, CE. Mr. F. R. Brown was Technical Director. 


\section{CONTENTS}

$\underline{\text { Page }}$

INTRODUCTION . . . . . . . . . . . . . . . . . . . 4

SAMPLES AND TESTS ...................... . . 6

RESULTS OF EXAMINATION WITH THE SCANNING ELECTRON MICROSCOPE . • . 9

RESULTS OF EXAMINATION BY X-RAY DIFFRACTION . . . . . . . . . . 12

DISCUSSION . . . . . . . . . . . . . . . . 16

CONCLUSIONS . . . . . . . . . . . . . . . . . 21

REFERENCES ........................ . . . 22

FIGURES $1-36$

TABLES $1-9$ 


\section{CONVERSION FACTORS, NON-SI TO METRIC (SI)}

UNITS OF MEASUREMENT

Non-SI units of measurement used in this report can be converted to metric (SI) units as follows:

Multiply

angstroms

torr

inches

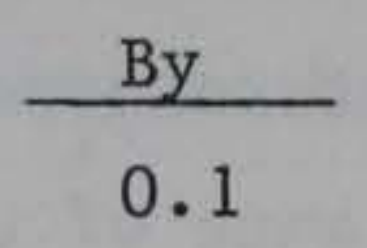

133.322

25.4
To Obtain

nanometres

pascals

millimetres 


\section{INVESTIGATION OF CEMENT PASTES AND RELATED MATERIALS BY \\ SCANNING ELECTRON MICROSCOPY AND X-RAY DIFFRACTION}

\section{INTRODUCTION}

1. The scanning electron microscope (SEM) permits the examination of surfaces of materials over a range of useful magnification from about $5 \mathrm{X}$ to $50,000 \mathrm{X}$. The application of SEM to cement and concrete research is relatively new and holds great potential. The great depth of focus of the SEM allows examination of fracture surfaces at magnifications much greater than are obtainable with the light microscope. Since the magnifications with the SEM are frequently so great, many materials look considerably different by scanning microscopy than they do by light microscopy. The visual contrast of the SEM image differs considerably from the contrast of an image obtained with a light microscope. Color differences between materials that are translucent or transparent or opaque, and differences in luster do not appear in the scanning electron microscope. Thus, much of the information available from light microscopy is not directly available to interpret SEM results. The compensating advantages of the SEM lie in the great depth of field and the ability to achieve high magnifications, which together offer possibilities in investigating the morphology of hydrated cement that are unavailable using light microscopy.

2. A problem encountered when examining hydrated cement and concrete with the SEM is that the materials are poor electrical conductors and must be coated with a conductive layer of metal or of carbon and metal. Proper drying techniques must be developed and followed to prevent the creation of artifacts and cracks which could easily cause misinterpretation of the SEM results.

3. The objectives of this study were to examine the hydration products of different types of cements and individual cement constituents to develop criteria for identifying these hydration products, to develop 
proper sample preparation techniques, and to initiate a data file of micrographs of hydrated cements and cement constituents.

4. All of the starting materials, and parts of each hydrated sample, were examined by X-ray diffraction (XRD), either as smooth ground slabs or as tightly packed powders, to permit better interpretation of the micrographs and to determine whether the phases produced in hydration were those to be expected in the hydration of the starting materials used. 
5. The samples used to prepare pastes were:

\section{Synthetic Materials}

Alite clinker;

"Ettringite anhydride"
Prepared by Alexander Klein in connection with research sponsored by the National Science Foundation, conducted at the University of California, Berkeley, California.

The cooperation of $\mathrm{Mr}$. Klein in providing these two samples was of great assistance.



6. Chemical analysis of the alite and chemical and physical analyses of the three cements are shown in Tables 1 through 4 . There was no chemical analysis of the ettringite-forming material.

\section{Sample Preparation}

7. The alite clinker was ground to pass a $45-\mu \mathrm{m}$ (No. 325) sieve before subsequent sample preparation took place. A sample of alite, of the ettringite-forming material, and of each cement was taken to represent the starting material. A portion of each sample was mixed as a paste at 0.5 water-solids ratio, placed in 3-in.-long plastic vials, and stored in a moist curing cabinet at 95 percent relative humidity, except that the Type $\mathrm{K}$ cement pastes were cast in rubber finger cots to allow for expansion. The hydrated pastes of alite and the ettringite-forming material were examined by SEM at ages of 1,3 , and 7 days, while the hydrated cements were examined at ages of $1,3,7$, and 28 days. Each vial or cot of paste was sawed axially and the two halves were placed in 
acetone to prevent further hydration. One-half of each sample was to be examined by $\mathrm{X}$-ray diffraction and the remaining half was to be examined by SEM. The top and bottom inch of each piece was discarded to reduce the effects of sedimentation. Each SEM sample was frozen in liquid Freon 12, fractured parallel to the direction of placement, and placed in a freeze-dry apparatus to sublime the ice.* The specimens were mounted on sample stubs with silver conductive paint and placed in a vacuum evaporator on a rotating tilting sample holder. At a vacuum of $5 \times 10^{-5}$ torr $\left(6.7 \times 10^{-3}\right.$ pascals), a $50-A^{* *}$ (approximate) layer of carbon and a 200-A (approximate) layer of 60 percent gold-40 percent palladium was deposited on each specimen. Then the specimens were stored in a nitrogenfilled dessicator until they were examined by SEM. The samples representing the starting material of each specimen were attached to the specimen stub with double-backed tape before they were coated with carbon and gold-palladium. As an experiment, a 3-day-old SEM sample of the ettringite-forming material was oven-dried at $105^{\circ} \mathrm{C}$ instead of being freeze-dried before being coated; another 3-day-old sample of this material was prepared as usual.

8. All of the samples were examined with an AMR-900 scanning electron microscope at an accelerating voltage of $21 \mathrm{kv}$.

9. The sawed surface of the hydrated samples of each specimen designated for XRD examination was ground smooth using abrasive dispersed in acetone. However, since the samples of hydrated ettringite-forming material crumbled during sawing, each XRD sample was ground to pass a 45- $\mu \mathrm{m}$ (No. 325) sieve and examined as a tightly-packed powder. The samples of starting materials were also examined as tightly-packed powders. Al1 of the XRD samples were examined in static nitrogen atmosphere in a vapor hood. A warm solution of $\mathrm{Ba}(\mathrm{OH})_{2}$ was placed in the hood with the hydrated samples to prevent carbonation and dehydration. All of the XRD patterns were made using a diffractometer with nickel-filtered copper radiation at 2.0 and again at $0.2 \mathrm{deg} / \mathrm{min}$ at a full-scale deflection of $\log 4000$.

\footnotetext{
* Present practice is to wait until after the specimen has been freeze-dried to fracture the surface that will be examined. ** 10 angstroms $=1$ nanometre.
} 
10. Selected samples of hydrated cement were polished and examined using a metallographic microscope. These samples were then coated with carbon and gold-palladium and examined with the SEM. No useful results were obtained from this procedure and it was deleted from the test program.

11. Standard cement chemists' notation was used as follows:
C for $\mathrm{CaO}$
A for $\mathrm{Al}_{2} \mathrm{O}_{3}$
$\mathrm{S}$ for $\mathrm{SiO}_{2}$
$\mathrm{F}$ for $\mathrm{Fe}_{2} \mathrm{O}_{3}$
$\underline{\mathrm{H}}$ for $\mathrm{H}_{2} \mathrm{O}$
$\underline{\mathrm{S}}$ for $\mathrm{SO}_{3}$
$\overline{\mathrm{C}}$ for $\mathrm{CO}_{2}$ 


\section{Alite}

12. The alite was ground to pass the 45- $\mu \mathrm{m}$ (No. 325) sieve and was almost certainly coarser than the two portland cements. At an age of 1 day, the partially hydrated alite grains were covered with calcium silicate hydrate (CSH) (Figure 1) which appeared as fibrous crystals covering original alite grains (Figures 2 and 3 ). These crystals had rounded ends and appeared to be oval to diamond shaped in cross section (Figure 3). Approximately 90 percent of the surface of the specimen was covered by clusters of CSH. After 3 days, most of these crystals had doubled in size and had more pointed ends than at 1 day (Figures 4 and 5 ). In the 7-day-old specimen there was little apparent change in the CSH (Figure 6). The clusters appeared to be interlocked more at 7 days and there were several patches of what was probably calcium hydroxide ( $\mathrm{CH}$ ) without obvious crystal outlines that had appeared since the examination of the 3-day specimen (Figure 7).

\section{Ettringite-Forming Material}

13. At 1 day, there was little recognizable in the way of crystal shape in the ettringite-forming material (Figures 8 and 9). Many large irregular grains were coated or partially coated with short rods of ettringite that were usually parallel to the substrate. The only major changes detected in the 3-day-old specimen was the presence of a few larger ettringite prisms (Figures 10 and 11). At 7 days, gypsum had developed and ettringite had increased. The texture of the sample was less porous (Figure 13). Some of the platy gypsum grains exhibited well developed crystal outlines (Figure 14).

14. The effect of oven-drying sample preparation on the 3-day-old specimen was small (Figure 12) as compared to other micrographs of this material. The recognition of new material in this sample was more difficult because of the persistence of gypsum and anhydrite during the time period used. 


\section{Type I Cement}

15. At 1 day, the partially hydrated cement grains were coated with $\mathrm{CH}$ and $\mathrm{CSH}$. The texture of the specimen was denser and more compact than the texture of alite paste at the same age. The $\mathrm{CH}$ was well developed at this age, but the $\mathrm{CSH}$ appeared restricted, with the clusters of crystals very small and disorganized (Figures 15 through 17) as compared to the alite hydrate and the Type $V$ paste. At 3 days, dense hydration product had filled much of the available pore space and had begun to engulf clusters of $\mathrm{CSH}$ (Figure 18). At 3 days, no ettringite was detected, but some small apparently hexagonal platelets which may be tetracalcium aluminate monosulfate-12-hydrate were present (Figure 19). The platelets resembled a similar structure in hydrated Type I cement paste illustrated and described by Diamond ${ }^{1}$ as probably being monosulfoaluminate. All platy hexagonal tetracalcium aluminate hydrates are expected to look alike. After 7 days, the texture of the specimen was more dense, with much of the available pore space filled with massive hydration products which have been described by Ciach et $\mathrm{al}^{2}$ as being material without determinate form composed of $\mathrm{CSH}$ and $\mathrm{CH}$. A similar conclusion was reached by Diamond. ${ }^{1}$ The amorphous looking material produced a massive texture in specimens at 7 and 28 days (Figures 20 through $22)$; it is believed to be $\mathrm{CH}$ intimately mixed with $\mathrm{CSH}$.

\section{Type V Cement}

16. At 1 day, about 90 percent of the cement grains were covered with clusters of CSH (Figures 23 through 25) and small patches of ettringite (Figure 24). After 3 days, most of the available pore space had been filled by $\mathrm{CSH}$ and $\mathrm{CH}$ (Figures 26 and 27). After 7 days, there was little apparent change in texture from the 3-day-old specimen except for the appearance of several well developed rods of ettringite (Figures 28 and 29). As in the Type I cement, at 28 days the Type $\mathrm{V}$ cement had developed a massive texture that was dominated by material without characteristic morphology similar to that described in the previous 
paragraph (Figure 30). Ettringite was present in the specimen (Figure 31), but there was no trace of the CSH clusters which were present at the early ages. They had presumably been encapsulated by the massive hydration product.

\section{Type $\mathrm{K}$ Cement}

17. The Type $\mathrm{K}$ pastes were cast in rubber finger cots and thus were not restrained during hydration. These pastes were consequently not comparable to Type $\mathrm{K}$ cements hydrated under restraint in concrete. At 1 day, the specimen was covered with many stubby prisms of ettringite and a few platelets of $\mathrm{CH}$. After 3 days, the only apparent change was a slight increase in the length of the ettringite prisms (Figures 32 and 33). However, after 7 days, the ettringite crystals had almost doubled in size and formed well developed prisms. There was only a slight reduction in pore space at this age. By 28 days, the ettringite was well developed both parallel to and normal to surfaces of the original cement grains. However, even at this age there was little change in pore space when compared to the 1 - and 3-day specimens (Figures 34 through 36). No micrographs of 1-day and 7-day specimens were successful; the specimens were examined but they tended to charge to a greater degree than most of the other specimens in the program.

18. The actual size of any features in the micrographs may be found by dividing the magnification by 1000; this value is then the number of $\mathrm{mm}$ on that micrograph that equals $1 \mu \mathrm{m}$. 
19. The XRD examinations were made to assist in interpreting the SEM results and to see how information from the two methods compared. Relative intensities of some XRD lines which were not interfered with were measured in chart units and recorded in the lower parts of Tables 5 through 9. Since the charts were made with the rate meter set to give a logarithmic response, it should be assumed that all minor constituents quantitatively expressed have been exaggerated in amount, and that the relation between trace and minor constituents and intermediate to abundant constituents is not correctly represented in the tables. Nonetheless, the detectable reduction of original constituents and development of hydration products in each material through times up to 28 or 56 days is indicated in these tables.

\section{Alite Clinker and Pastes}

20. The chemical analysis of the clinker after at least 7 years of storage is shown in Table 1 and the phase composition by XRD in Table 5. Minor hydration of the starting material in storage was shown by the presence of traces of $\mathrm{CH}$ and tetracalcium aluminate carbonate-11hydrate in the clinker.

21. The crystal system of the alite was investigated by scanning the lines between 51.5 and 52.0 degrees two-theta in several packings using the 3-degree beam slit with the high-resolution soller slit and the 0.05-degree detector slit and several different linear vertical scales, time constants, and chart speeds. All the packings indicated two lines but in some packings the line at lower angle was the stronger of the two and in others the situation was reversed. Considering all the results it appeared that the starting material contained both monoclinic and inverse monoclinic alites by the criteria of Guinier and Regourd. 3

22. Table 5 shows the constituents identified in the original clinker and pastes and changes in the pastes. The belite line at 
31 degrees two-theta is not interfered with except possibly by alkali sulfates; this 1 ine is at $2.88 \mathrm{~A}$ for copper radiation and is fairly weak and rapidly masked in hydrating cements by the elevation of the background during hydration. For this reason the line at 41.40 degrees two-theta, $2.18 \mathrm{~A}$, containing strong lines of alite and belite was used to provide some information on the hydration of the small amount of belite in this clinker. The X-ray data (Table 5) indicated that the hydration products were $\mathrm{CH}$ and $\mathrm{CSH}$.

\section{Ettringite-Forming Material}

23. The composition of the ettringite-forming material examined in the condition in which it existed after several years of storage is shown in Table 6 . The original composition almost certainly consisted of tetraclacium trialuminate sulfate $\left(\mathrm{C}_{4} A_{3} \bar{S}\right)$, anhydrite, and calcium oxide with a trace of periclase; the six substances listed as alteration products were produced by reaction with $\mathrm{CO}_{2}$ and moisture. The diffraction charts indicated that the ultimate limit on formation of ettringite in the hydration product arose from the apparent exhaustion of calcium oxide and $\mathrm{CH}$ by 3 days and the apparent exhaustion of $\mathrm{C}_{4} \mathrm{~A}_{3} \overline{\mathrm{S}}$ at 28 days. Both anhydrite and gypsum were present at 28 days. The lack of silica in this material is the reason no sign of $\mathrm{CSH}$ was found or expected.

\section{A Type I Cement and Its Hydration Products}

24. Table 2 shows the chemical analyses and physical tests of this cement. Table 7 shows the original constituents and the hydration products and their changes in amount. The cement contained 13.8 percent calculated tricalcium aluminate $\left(\mathrm{C}_{3} \mathrm{~A}\right)$ and 2.3 percent $\mathrm{SO}_{3}$; at $24 \mathrm{hr}$, monosulfoaluminate $\left(\mathrm{C}_{4} \mathrm{~A}_{\mathrm{S}}{ }_{12}\right)$ predominated over ettringite in the diffraction pattern and increased to 28 days because of the low sulfate to high $\mathrm{C}_{3} \mathrm{~A}$ content. Hydrogarnet was recognized at 3 days and thereafter; CSH was recognized at 7 and 28 days. The calcium aluminoferrite solid solution in the cement diminished in amount to 7 days but about the same quantity was present at 28 as at 7 days. Several hydration products of 
tricalcium aluminate were present, forming a hump at higher angle than the $\mathrm{C}_{4} \mathrm{AS}_{12}$ line at 9.9 degrees two-theta but continuous with it and running to about 11.8 degrees two-theta; the probable compounds in that hump were tetracalcium aluminate hydroxysulfate hydrate, tetracalcium aluminate-13-hydrate, tetracalcium aluminate hemicarbonate-12-hydrate, and tetracalcium aluminate monocarbonate-11-hydrate. ${ }^{4} \mathrm{CH}$ was a major component of all the X-ray patterns of the hydrated material.

\section{A Type V Cement and Its Hydration Products}

25. Chemical analyses and physical tests are shown in Table 3; the XRD results appear in Table 8. The unhydrated cement consisted of alite, belite, a member of the calcium aluminoferrite solid solution series, gypsum, calcium sulfate hemihydrate, and a trace of calcite and ettringite. No $\mathrm{MgO}$ was detected. Belite could not be unequivocally detected during hydration. The cement contained abundant alite and relatively little belite. During hydration the belite spacing at $2.88 \mathrm{~A}$ was masked by the increasingly higher X-ray background of the hydrated samples. The intensity of the alite line at $1.76 \mathrm{~A}$ fell below the intensity of the combined alite and belite line at $2.18 \mathrm{~A}$ between 3 and 7 days. The difference in intensity of the $2.18-\mathrm{A}$ and the $1.76-\mathrm{A}$ lines from 7 through 28 days shows the slower hydration of belite. The hydration of the calcium aluminoferrite in this cement was apparently negligible after 3 days. The presence of $\mathrm{CH}$, ettringite, and $\mathrm{CSH}$ with calcium aluminate hydrates with and without additional anionic groups which were tentatively identified at different ages is shown in Table 8 .

\section{A Type K Self-Stressing Cement and Its Hydration Products}

26. Chemical analysis and some physical tests of this cement are shown in Table 4 and the composition determined by XRD is shown in Table 9. While the cement was in storage before the pastes were made, part of the calcium oxide had hydrated to $\mathrm{CH}$, dehydrating all of the gypsum to $\mathrm{CaSO}_{4}-1 / 2 \mathrm{H}_{2} \mathrm{O}$. In the paste at 1 day, gypsum was fairly abundant but it 
decreased in pastes cured to greater ages. Tetracalcium trialuminate sulfate $\left(\mathrm{C}_{4} \mathrm{~A}_{3} \overline{\mathrm{S}}\right)$ decreased sharply to 1 day and more slowly thereafter; if the decrease continued at the rate indicated after 3 days, the compound should be exhausted before 2 months. The decrease in calcium sulfate is shown in Table 9 but is not regarded as entirely trustworthy because the calcium sulfate line used is located in a region of the pattern in which intensity should increase with continued curing as CSH is produced. The hydration products of this cement differed from those in the ettringite-forming material discussed earlier in that some $\mathrm{CH}$ was present in the Type $\mathrm{K}$ hydrate while none was detected in the ettringite-forming material after 1 day. 
27. The scanning electron microscopy of hydrated cements and hydrated cement constituents can be interpreted by reference to transmission electron microscopy of replicas of hydrated cements, to light microscopy of hydrated cements, by comparison with published SEM micrographs, and by reference to the composition of the hydration products as determined by XRD. Transmission electron microscopy of dispersed hydrating cement and cement constituents has given valuable information on the detailed morphology of hydration products and formed the foundation needed to interpret SEM micrographs. Transmission electron microscopy of replicas of hydrating cement grains ${ }^{5}$ and of pastes ${ }^{2,6,7,8}$ has shown stages in the development of dense paste and given information on the morphology and interrelation of calcium aluminate-ferrite sulfate hydrates which can be directly related to scanning micrographs.

28. One of the best ways to interpret SEM micrographs is to have an X-ray detector as an integral part of the SEM to provide compositional data. Lacking this interpretation may be done by direct comparison with SEM micrographs containing known materials or by correlation with XRD data or both.

29. Mills, ${ }^{9}$ Diamond, ${ }^{10}$ and Williamson ${ }^{11}$ have illustrated in scanning electron micrographs radial or spherulitic aggregates of CSH fibers like those shown in Figures 2 through 7 (hydrated alite), 16, 17 (hydrated Type I cement) and Figures 23 through 25 (hydrated Type V cement). Diamond ${ }^{10}$ used a SEM equipped with an energy-dispersive X-ray detector to establish that the sulfur in $\mathrm{CSH}$ produced from cements ground with a form of calcium sulfate can be detected in the radiating clusters of CSH fibers, and can also be detected in dense apparently massive $\mathrm{CH}-$ $\mathrm{CSH}$ crystals which encapsulate gel. This dense looking material which sometimes shows parallel cleavage traces appears to be the most conspicuous feature of the 0.5 water-cement ratio pastes at 7 and 28 days. 30. Brown and Carlson ${ }^{13}$ observed in 1936 what other light microscopists working on portland cement concretes had possibly observed before and have certainly observed since: In thin sections of concretes 
or mortars it is usually clear that $\mathrm{CH}$ crystals growing in areas of paste contain many CSH gel inclusions; such $\mathrm{CH}$ crystals appear to be sponge-1ike in three dimensions; "poikilitic" is the petrographic term. Figure 1 of Reference 7 shows the same kind of texture in an electron micrograph of a carbon replica of paste. Copeland et al ${ }^{6}$ have shown that sulfate can enter CSH. These observations together appear to provide background for Diamond's detection of sulfur in CSH and in the apparently massive material that resembles $\mathrm{CH}$.

31. Diamond ${ }^{10}$ recorded the $\mathrm{Ca}: \overline{\mathrm{S}}$ ratio of two samples of synthetic ettringite as averaging 1.95 or 1.96 . We have examined ettringite in void fillings from deteriorated concrete subjected to sulfate attack; Diamond examined another portion of the same ettringite with SEM using an energy dispersive X-ray spectrometer system and found the same ca1cium to sulfur ratios as in the synthetic ettringite; ${ }^{12}$ his micrographs of these showed hexagonal prisms where cross sections or ends of crystals could be recognized. He has since published an SEM micrograph showing ettringite crystals ${ }^{14}$ similar to those just described. Diamond has also noted material that was apparently a circular $\mathrm{CH}$ in hydrated cement paste. ${ }^{10}$ Therefore, it seems reasonable to be extremely cautious in interpreting needles with parallel sides as ettringite unless it is possible to determine the calcium to sulfur ratio as about 1.96 , or to identify the ettringite by light microscopy, or to demonstrate by $\mathrm{XRD}$ that ettringite is present but $\mathrm{CH}$ is not. The third situation is not to be expected in hydrated portland cements. The first and second possibilities exist with respect to some void fillings but do not exist if one wishes to identify the minute ettringite prisms formed within the paste of hydrating portland cements. In the case of the material that hydrated to form ettringite as the principal product, $\mathrm{CH}$ could not be positively detected by XRD after 1 day. In Figure 14, several hexagona1 cross sections of rods can be perceived; in a 7-day sample the XRD results on another part of this sample (Table 6) contained abundant ettringite and no other crystalline constituent capable of forming hexagonal prisms. Figure 35, a hydrated Type $\mathrm{K}$ cement at 28 days, shows well developed hexagonal needles in a sample that contained more ettringite 
than any other crystalline constituent but contained $\mathrm{CH}$ as the next most abundant crystalline constituent. Generally, the elongated prisms seen in the present micrographs were interpreted as ettringite.

32. In the discussion of specimens of the hydrated Type I cement the presence of small thin plates resembling some figured by Copeland and Kantro ${ }^{8}$ as $\mathrm{C}_{4}(\mathrm{~A}, \mathrm{~F}) \overline{\mathrm{SH}}_{12}$ and by Diamond ${ }^{1}$ as possibly tetraclacium aluminum monosulfate-12-hydrate is mentioned; they are shown in Figure 19. Both identifications are probable as applied to the hydrated Type I cement examined here, since tetracalcium aluminum monosulfate hydrate increased in the XRD patterns from 1 day through 28 days. Tetracalcium aluminate monosulfate-12-hydrate is only one of several platy hexagonal calcium aluminate hydrates and calcium aluminate hydrates with additional anionic groups that may be expected to form similar hexagonal plates. Some of these other hydrates were present in the 3-day specimen of Type I cement although tetracalcium aluminate monosulfate-12-hydrate was by far the most abundant. All that can be concluded with certainty is that platy hexagonal calcium aluminate hydrates, with and without additional anions, were present and the micrograph (Figure 19) probably shows the most abundant one.

33. Examination of the samples by XRD assisted in the interpretation of the scanning micrographs by providing information on the phase composition of the samples before hydration and at stages during hydration. The hydration products identified in the hydrated cements and the synthetic materials by XRD were those which were to be expected in the SEM micrographs.

34. An additional observation, new to us, was that if it is desired to compare intensities in XRD patterns as peak height minus background as a measure of alteration of original constituents in diffraction charts of hydrating cements or synthetic cement constituents, it seems to be preferable to use the background level of the original waterfree material throughout the comparison. In these samples, each of the hydrated samples, regardless of age, had higher background than the unhydrated starting material. The background levels, measured at two points, increased from 1 through 3 days and thereafter decreased. Since 
the maximum and minimum intensities on the diffractometer chart were adjusted every morning and the power setting of the instrument reset if necessary to give constant intensity on a fine-grained quartz slab used as an external standard, it seems reasonable to believe that the fluctuation in the background level was related to the sample and not to electronic instability. It is probable that the increase in background level of the X-ray charts of the hydrated samples was due to the presence of the water in them. We have observed similar changes in X-ray patterns of soil samples at different water contents.

35. In 1976, Diamond ${ }^{14}$ presented a comprehensive discussion of the microstructure of cement paste with several SEM micrographs. Comparison of the present results with those and with his earlier work ${ }^{1}$ indicates the following:

a. The structures seen in the appropriate micrographs showed general similarities.

b. Diamond's use of both oven-drying and vacuum-drying and our use of freeze-drying during specimen preparation all produced similar results. This suggests that the micrographs are valid representations of actual microstructures at the water contents used. It is believed that these ratios of 0.5 or 0.6 for water to cement or solids produce microstructures like those found in the cement paste of actual field concretes. Our limited use of oven-drying as a specimen preparation technique agreed with what has just been stated about this technique.

36. Diamond ${ }^{14}$ and Mather and co-workers ${ }^{15}$ have both commented to the effect that as hydration of cement continues with time, the structure seen by SEM becomes dense and featureless. The same was true in this work for the Type I and the Type V cements. This was not true of the alite or the ettringite-forming material at 7 days or of the Type $\mathrm{K}$ cement at 28 days; they all still showed a more open structure at these ages. The encapsulation by $\mathrm{CH}$ and $\mathrm{CSH}$ that is commonly noted in cement pastes was less developed in the alite and the Type $K$ sample and was entirely lacking with the ettringite-forming material since $\mathrm{CH}$ was not formed in that material when it hydrated.

37. Comparison of our SEM micrographs of alite (substituted tricalcium silicate) with those of Lawrence and Young ${ }^{16}$ of pure tricalcium 
silicate are in good agreement which indicates that the substituents had no significant effect on the microstructures that were observed. 
38. Three nonexpansive cementitious and two expansive cementitious materials have been examined before and after hydration to observe their microstructures and composition. This was done by SEM and by XRD with the emphasis on the examination of the hydrated materials. As a result of this work, the following conclusions seem appropriate:

a. The present results are in good agreement with previous results found by others. $\mathrm{CH}$, ettringite, and various types of CSH are usually recognizable by their morphology in SEM micrographs. Various other hydrated compounds may also be recognized in such micrographs but less readily.

b. SEM examination of fractured surfaces of hydrated materials is an excellent way to study their microstructure and to follow changes in microstructure with time.

c. It is preferable that such examinations be augmented by auxiliary techniques such as an X-ray emission detector, or by XRD data. However, lacking these, fairly satisfactory interpretations may be made by comparison with other SEM micrographs for similar materials.

d. The SEM micrographs in this report will serve as reference micrographs for future comparisons.

e. The SEM examination of sawed and polished surfaces of these hydrated materials did not provide useful results.

f. The Type I and Type V cements developed dense, massive microstructures within the times used whereas the other three expansive materials still showed more open and porous microstructures at 7 - and 28-day ages.

g. The hydration products of the alite, the Type I, and the Type $\mathrm{V}$ cements included large amounts of CSH while hydration of the ettringite-forming material and the Type $\mathrm{K}$ cement produced large amounts of ettringite.

h. Calcium silicate hydrate was not specifically recognized in the hydrated Type $K$ expansive cement although it would be expected since portland cement is a major constituent of Type $\mathrm{K}$ cement. 


\section{REFERENCES}

1. Diamond, S., "Application of Scanning Electron Microscopy to the Study of Hydrated Cement," in Proceedings of the Third Annual Scanning Electron Microscope Symposium, Chicago, I11., 1970, pp 385392.

2. Ciach, T. D., Gillott, J. E., Swenson, E. G., and Sereda, P. J., "Microstructure of Hydrated Portland Cement," in Cement and Concrete Research, Vo1 1, 1971, pp 13-25.

3. Guinier, A. and Regourd, M. , "Structure of Portland Cement Minerals," Proceedings Fifth International Symposium on the Chemistry of Cement, Tokyo, 1969, Vol 1, pp 1-32.

4. Seligmann, Paul, and Greening, Nathan R., "Studies of Early Hydration Reactions of Portland Cement by X-Ray Diffraction," Highway Research Record, 62, 1964, pp 80-105.

5. Czernin, Wolfgang, "A Few Unsolved Problems in Cement Hydration," Proceedings of the Fourth International Symposium on the Chemistry of Cement, Washington, 1960, Vol II (1962), pp 725-729.

6. Copeland, L. E., Bodor, E., Chang, T. N., and Weise, C. H., "Reactions of Tobermorite Gel with Aluminates, Ferrites, and Sulfates," Journal of the PCA Research and Development Laboratories, Vol 9, No. 1, Jan 1967, pp 61-74.

7. Verbeck, G. J. and Helmuth, R. H., "Structures and Physical Properties of Portland Cement Paste," Fifth International Symposium on the Chemistry of Cement, Vol III, pp 3, 1968.

8. Copeland, L. E. and Kantro, D. L., "Hydration of Portland Cement," Fifth International Symposium on Chemistry of Cement, Vol II, pp 387-420, 1968.

9. Mills, R. H., "Influence of Water in Areas of Restricted Adsorption on Properties of Concrete," University of Calgary Faculty of Engineering Technical Publications, no date (1968).

10. Diamond, Sidney, "Analysis of Hydrated Cements Using a Scanning Electron Microscope - Energy - Dispersive X-Ray Spectrometer Combination," Joint Highway Research Project Report No. 21, December 1971, Purdue University and Indiana Highway Commission.

11. Williamson, Robert Brady, "Solidification of Portland Cement," Report No. UC SESM 70-23, 1970, Structural Engineering Laboratory, University of California, Berkeley, Calif.

12. Diamond, Sidney, personal communication, Dec 1971.

13. Brown, L. S., and Carlson, R. W., "Petrographic Studies of Hydrated Cements," Proceedings, American Society for Testing and Materials, Vol 36, Part II, 1936. 
14. Diamond, S., "Cement Paste Microstructure - An Overview at Several Levels," p 28, Fig. 9, in Hydraulic Cement Pastes: Their Structure and Properties, Cement and Concrete Association, Apr 1976.

15. Mather, K., Burkes, J. P., Wong, G. S., and Reinhold, R., "Effects of Accelerated Curing on Hydration Products of Cement and CementF1y Ash Pastes," U. S. Army Engineer Waterways Experiment Station, CE, Miscellaneous Paper C-78-11, Vicksburg, Miss., Aug 1978.

16. Lawrence, F. V. and Young, J. F., "Studies on the Hydration of Tricalcium Silicate Pastes 1. Scanning Electron Microscopic Examination of Microstructural Features," Cement and Concrete Research, Vo1 3, pp 149-161, 1973. 


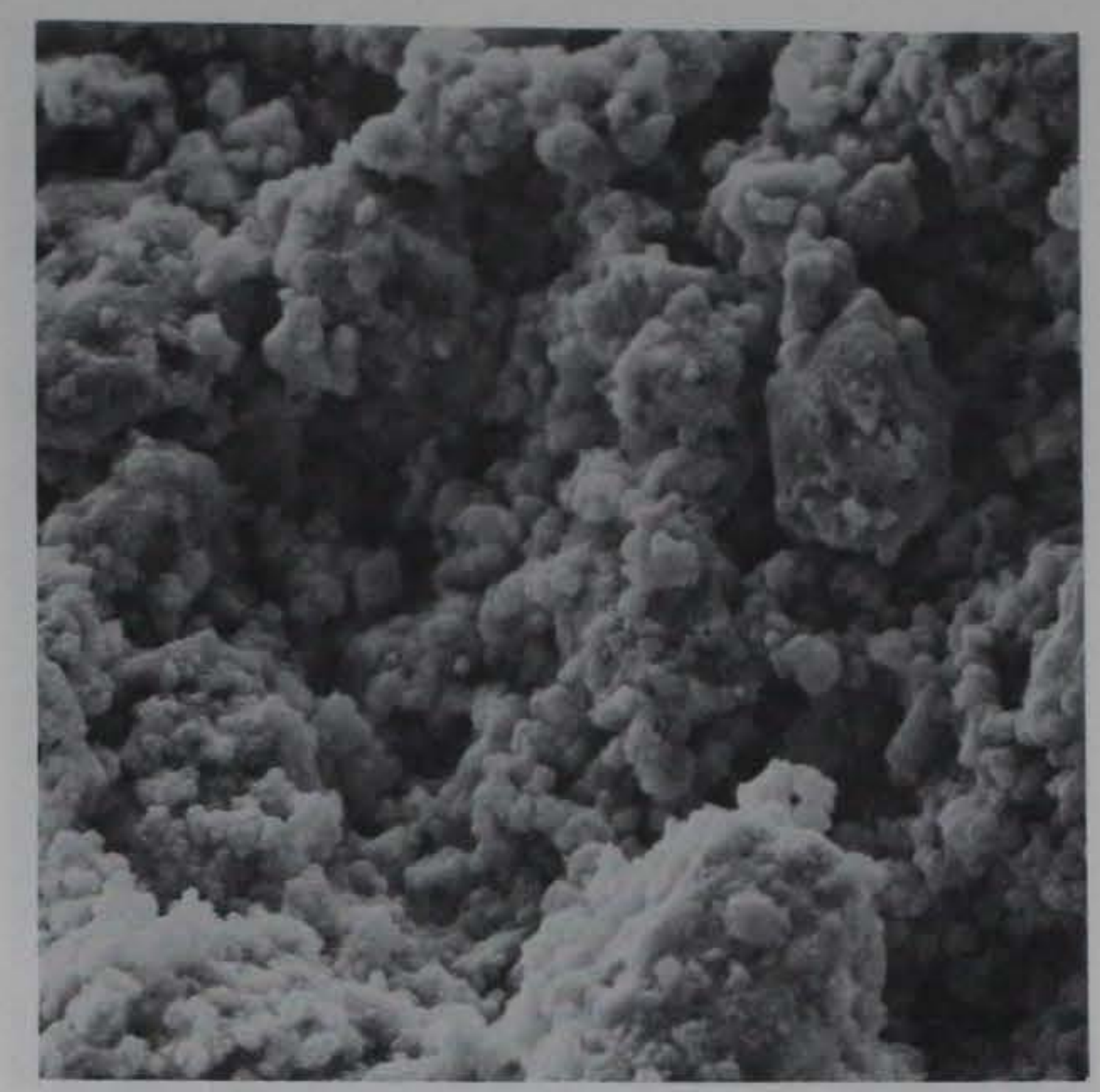

Figure 1. Alite, hydrated at $0.5 \mathrm{~W} / \mathrm{C}$. Specimen aged 1 day. Specimen was quite porous as the grains were loosely cemented by a surface layer of calcium silicate hydrate (500x)



Figure 2. Alite, hydrated at $0.5 \mathrm{~W} / \mathrm{C}$. Specimen aged 1 day. Higher magnification of center of Figure 1 showing coating of calcium silicate hydrate (5000X) 




Figure 3. Alite, hydrated at $0.5 \mathrm{~W} / \mathrm{C}$. Specimen aged 1 day. Area shown is in the right center of Figure 2 and shows detail of the calcium silicate hydrate; it is probably fibrous Type I. 14 The diameters of the fiber bundles appear to be about $0.1 \mu \mathrm{m}$ and the length up to $0.3 \mu \mathrm{m}$ $(10,000 x)$ 


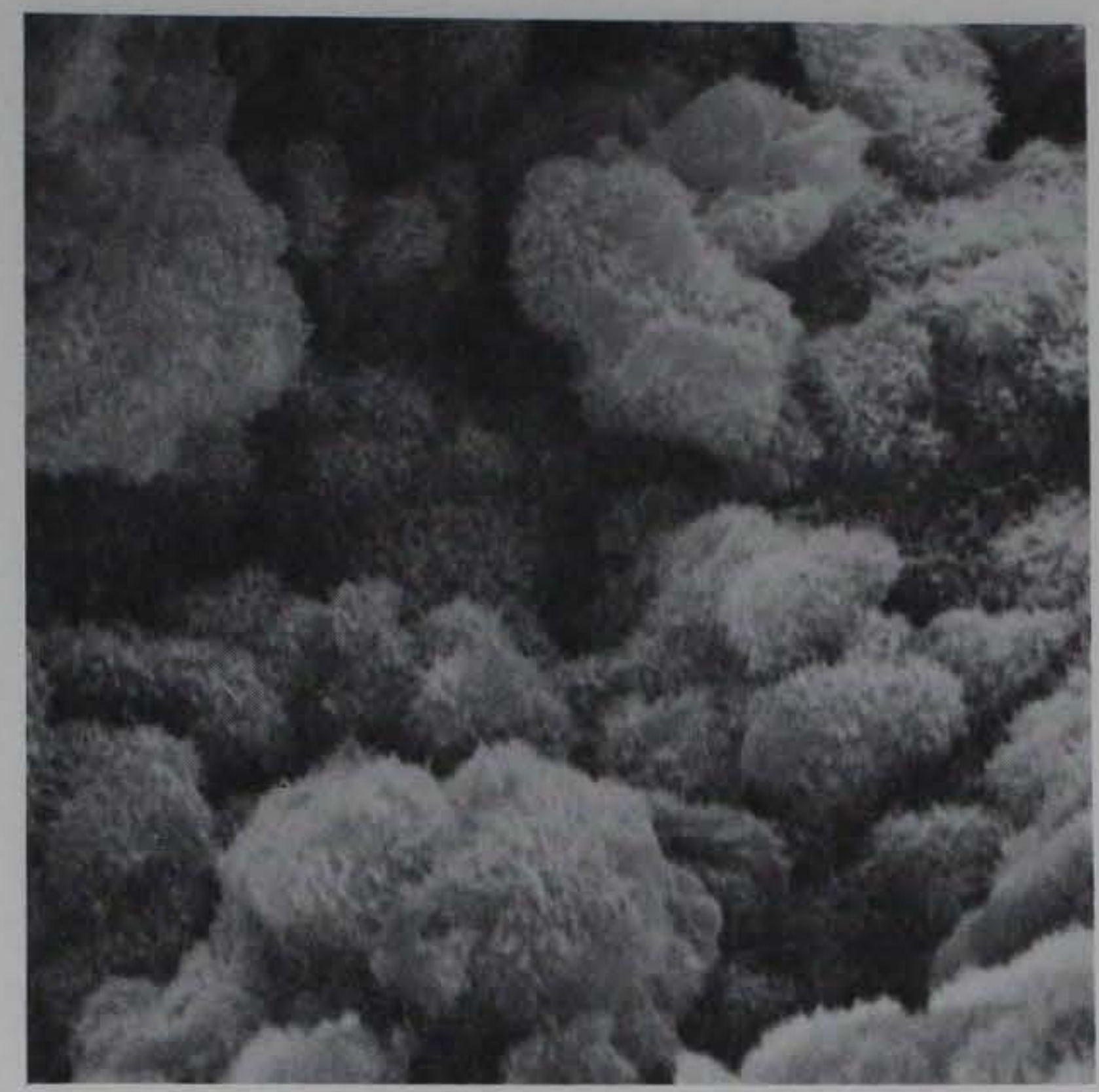

Figure 4. Alite, hydrated at $0.5 \mathrm{~W} / \mathrm{C}$. Specimen aged 3 days. Grains are becoming interlocked as the needles of calcium silicate hydrate begin to grow together. The smooth particles in the upper right are small grains of calcium hydroxide (5000X)

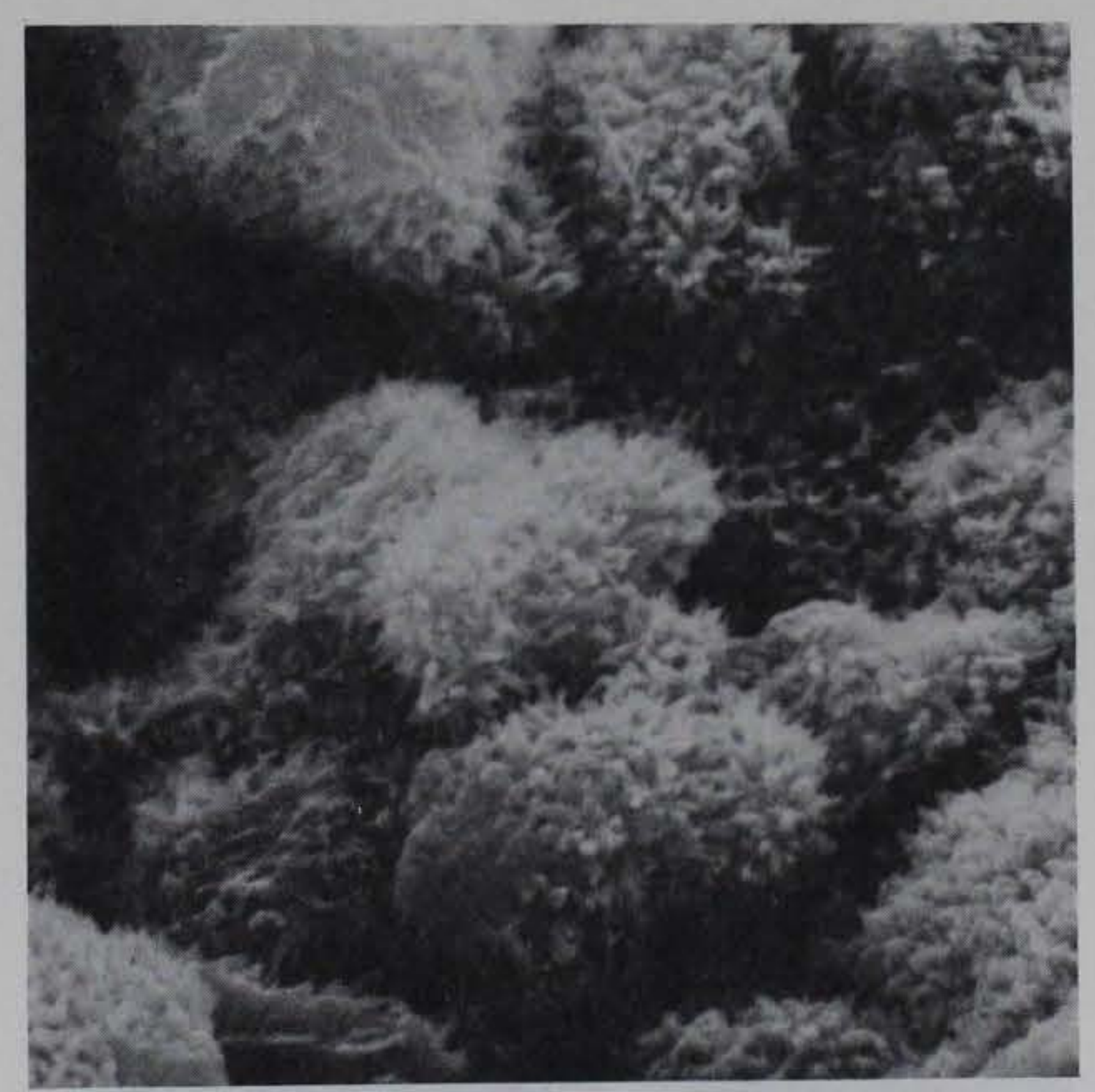

Figure 5. Alite, hydrated at $0.5 \mathrm{~W} / \mathrm{C}$. Specimen aged 3 days. Area shown is in the right center of Figure 4. In this area the clusters of fibrous Type $\mathrm{I}^{14}$ calcium silicate hydrate were well developed, which was typical of this specimen. Lengths of the fiber bundles range from $0.35 \mu \mathrm{m}$ to

$$
0.65 \mu \mathrm{m}(10,000 \mathrm{x})
$$






Figure 6. Alite, hydrated at $0.5 \mathrm{~W} / \mathrm{C}$. Specimen aged 7 days. This specimen shows a slight reduction in pore space as the clusters of calcium silicate hydrate have grown closer together. Also, calcium hydroxide grains are becoming more apparent at this age (2000X)

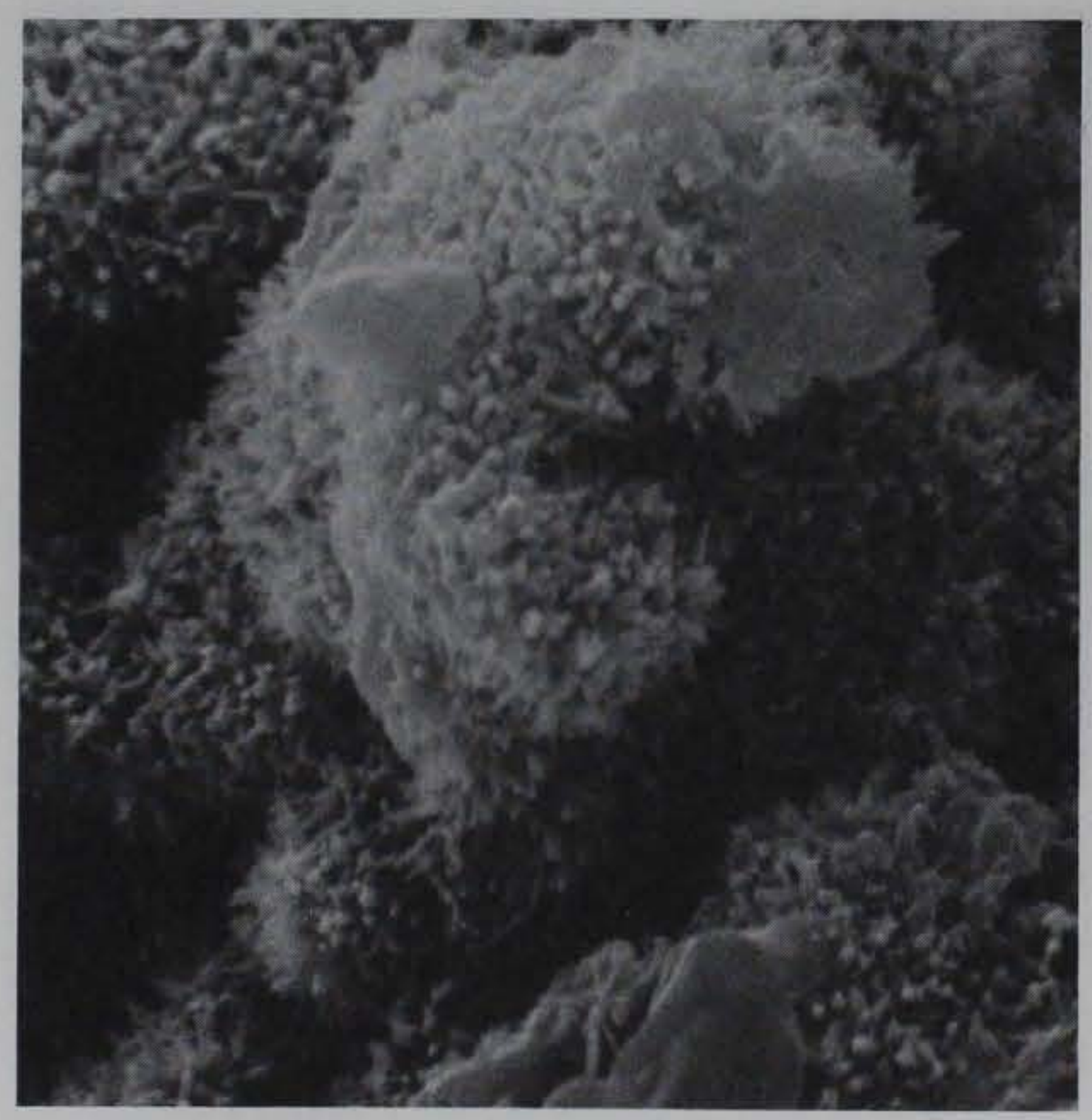

Figure 7. Alite, hydrated at $0.5 \mathrm{~W} / \mathrm{C}$. Specimen aged 7 days. This area is in the center of Figure 6 and shows the development of fibrous Type I 14 calcium silicate hydrate and platy calcium hydroxide $(10,000 \mathrm{x})$ 


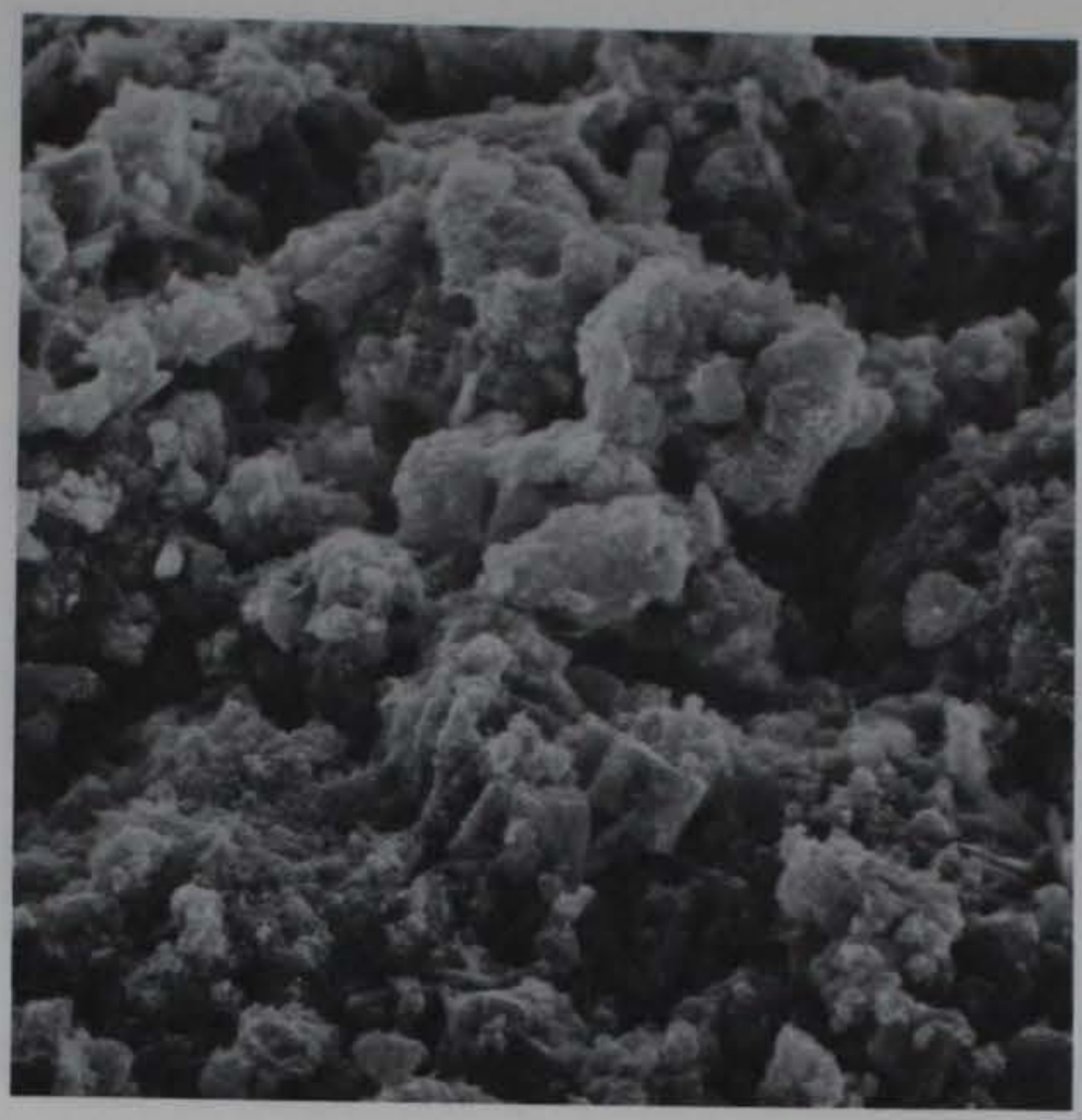

Figure 8. Ettringite-forming material, hydrated at $0.5 \mathrm{~W} / \mathrm{C}$. Specimen aged 1 day. This area shows the porous texture and some ettringite reaction product on grain surfaces. Below the center are several crystals which may be residual anhydrite (2000x)

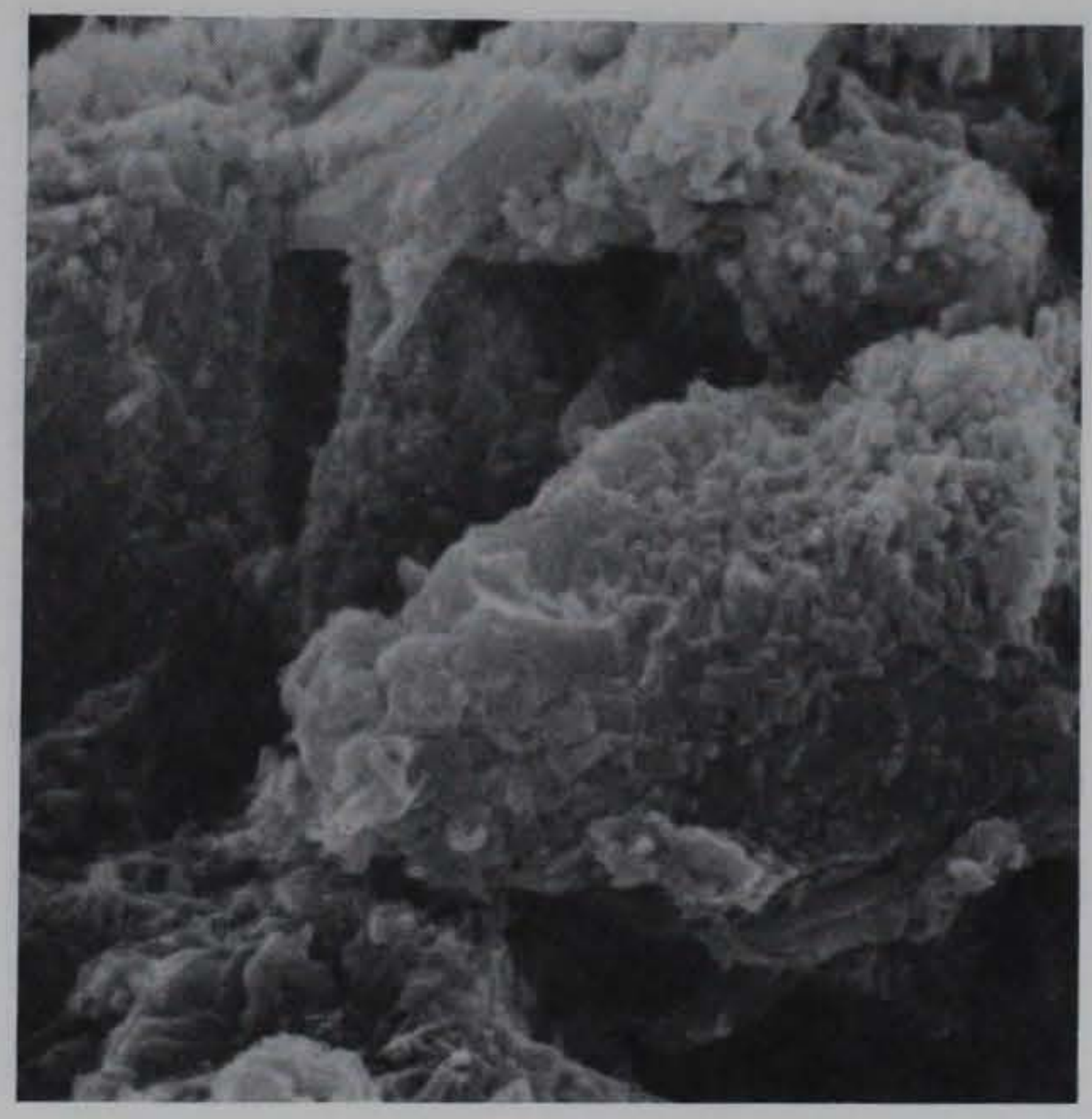

Figure 9. Ettringite-forming material, hydrated at $0.5 \mathrm{~W} / \mathrm{C}$. Specimen aged 1 day. The area shown is in the center of Figure 8. The small ettringite rods are very short and appear to have grown parallel to the surface of the grains which was typical in this sample. The larger blocky grain in the top of the figure may be residual anhydrite. This crystal is $0.25 \mu \mathrm{m}$ thick $(10,000 \mathrm{X})$ 


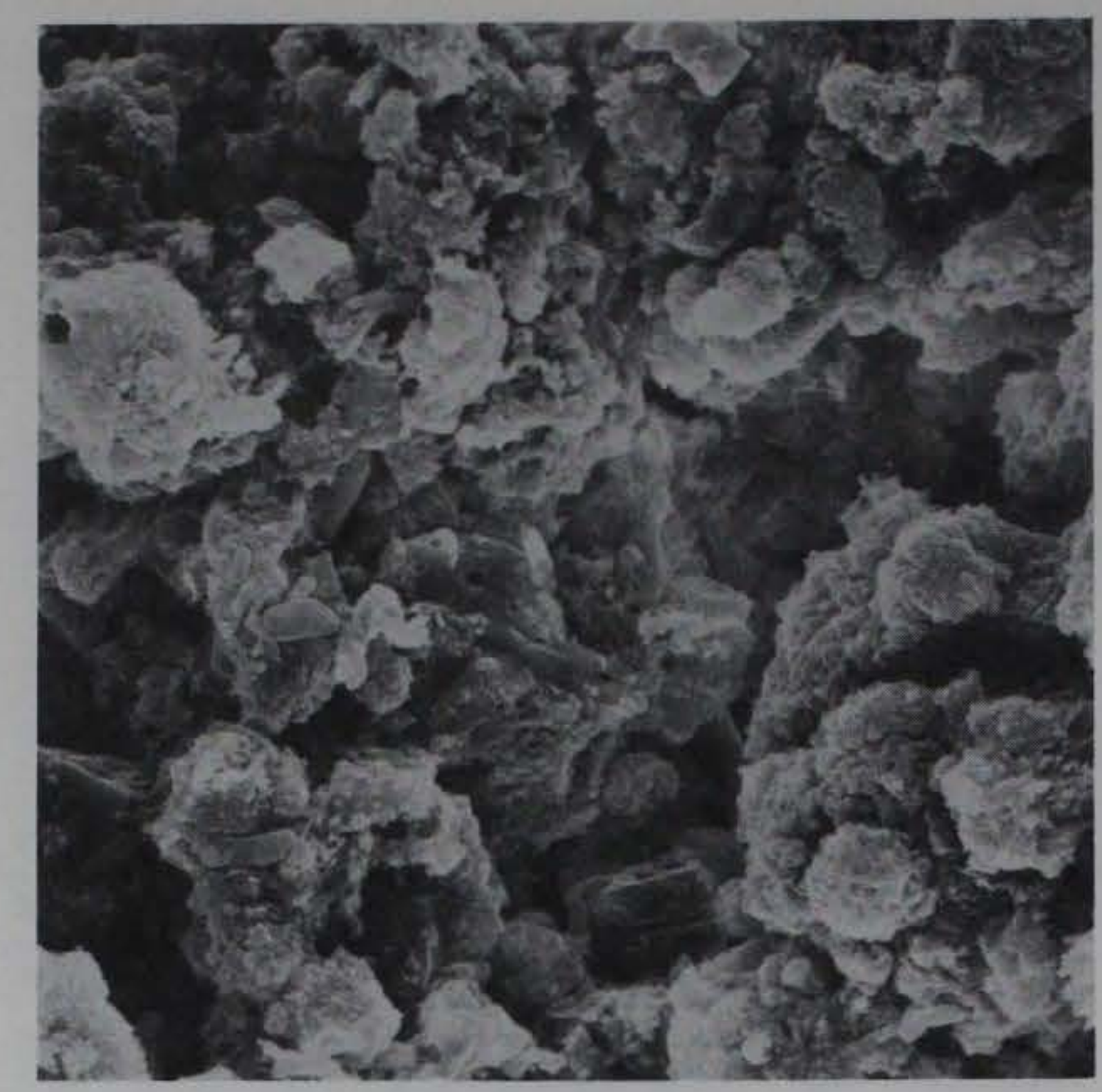

Figure 10. Ettringite-forming material, hydrated at $0.5 \mathrm{~W} / \mathrm{C}$. Specimen aged 3 days. This area shows the increased development of gypsum (?) and the presence of a few larger prisms of ettringite which developed normal to the grain surfaces (2000X)

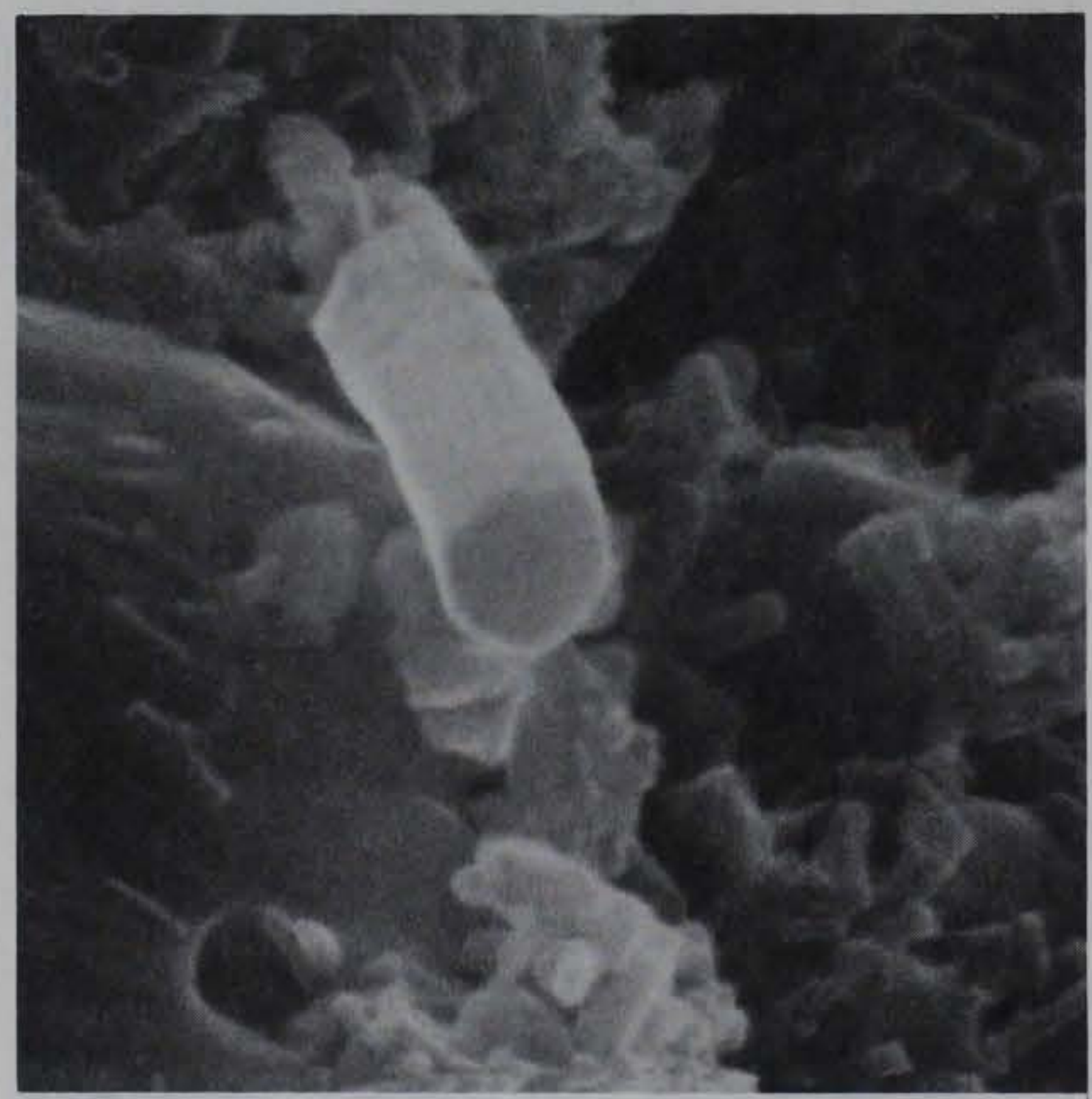

Figure 11. Ettringite-forming material, hydrated at $0.5 \mathrm{~W} / \mathrm{C}$. Specimen aged 3 days. This is the center part of Figure 10 . In the center of this figure is a rod of ettringite with a hexagonal cross section. This rod, $1 \mu \mathrm{m}$ in length, developed normal to the grain surface, while the majority of the smaller rods developed parallel to the grain surface and were typically $0.4 \mu \mathrm{m}$ in length $(20,000 \mathrm{X})$ 


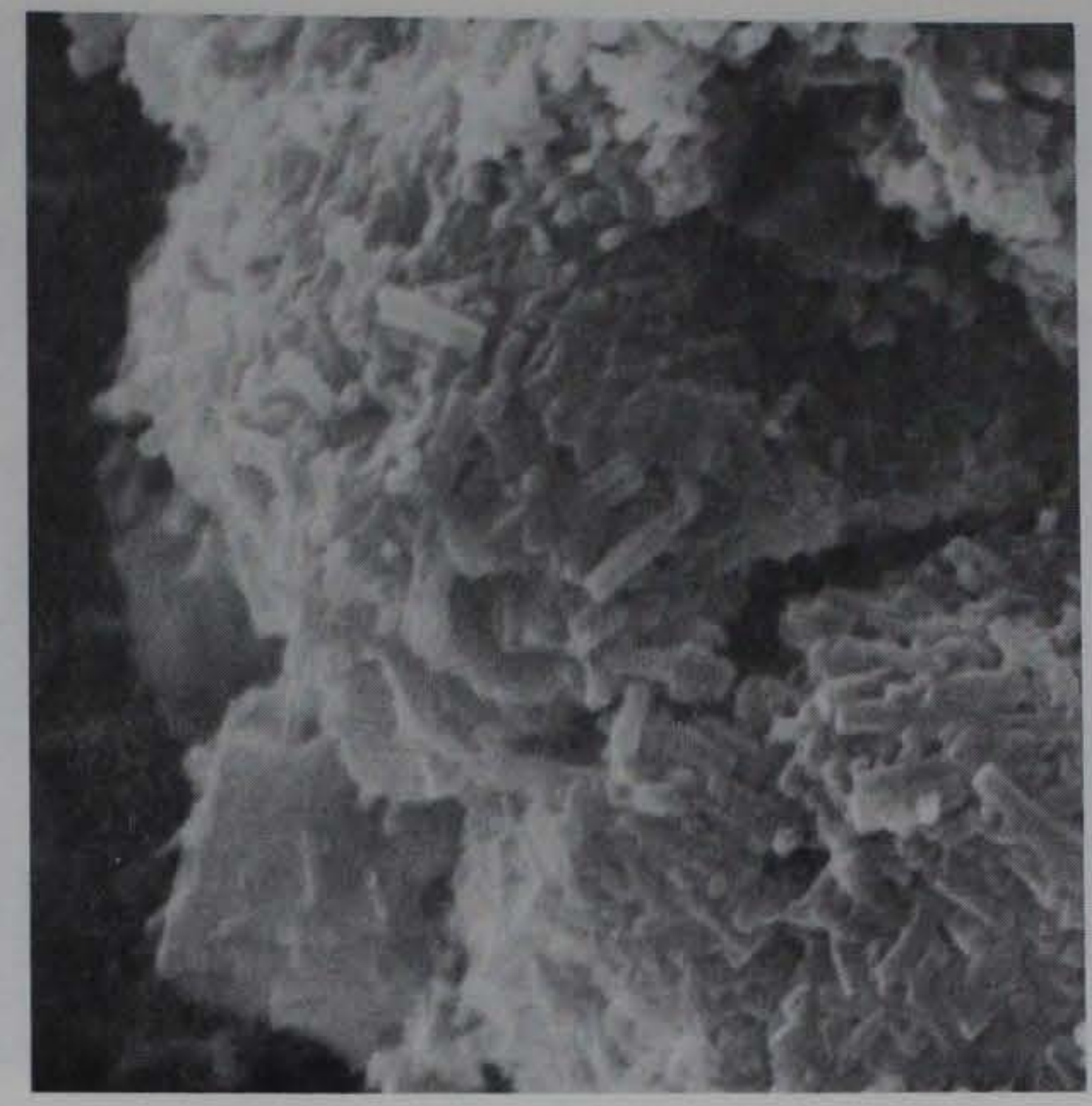

Figure 12. Ettringite-forming material, hydrated at $0.5 \mathrm{~W} / \mathrm{C}$. Specimen aged 3 days. It was dried in an oven at $105^{\circ} \mathrm{C}$ instead of being freezedried before being coated. The structure and ettringite reaction product seen are similar to those in Figure $9(10,000 \mathrm{X})$ 


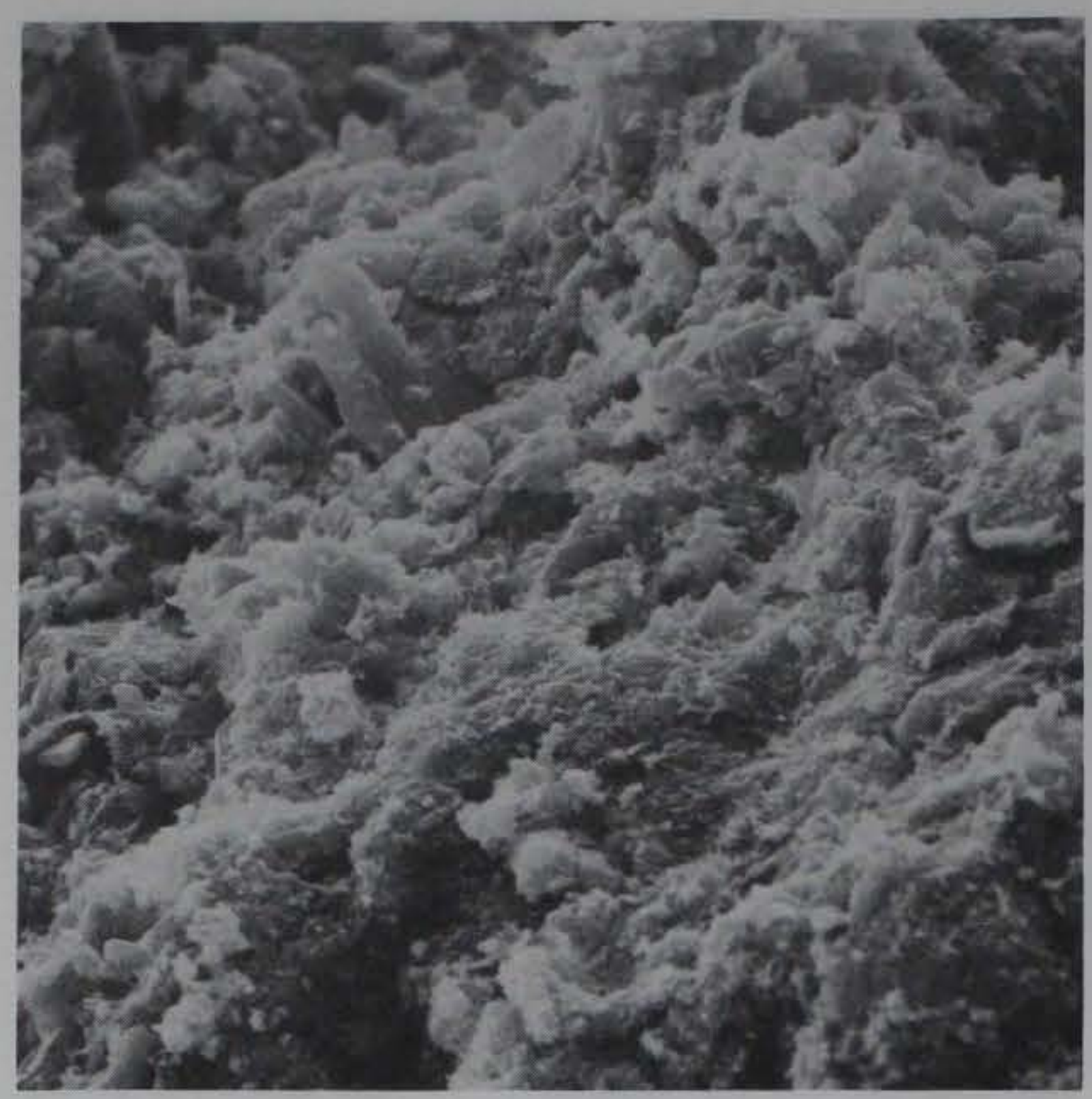

Figure 13. Ettringite-forming material, hydrated at $0.5 \mathrm{~W} / \mathrm{C}$. Specimen aged 7 days. The specimen has developed a more massive texture by this age (2000X)

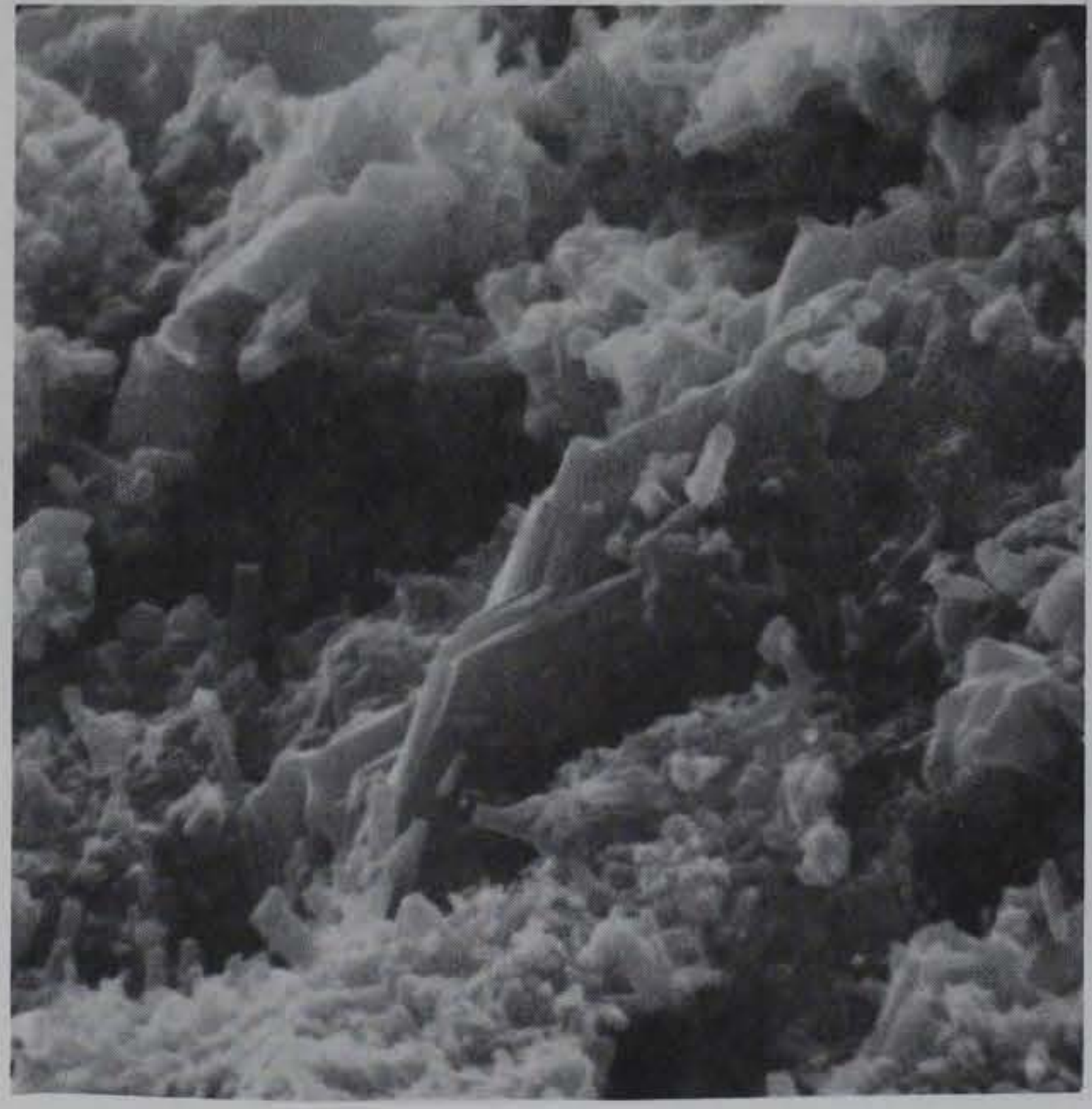

Figure 14. Ettringite-forming material, hydrated at $0.5 \mathrm{~W} / \mathrm{C}$. Specimen aged 7 days. This area is in the center of Figure 13 and shows several well developed platy grains of gypsum (?). Also, there are numerous rods of ettringite that are developing normal to the grain surface. These rods are typically $0.25 \mu \mathrm{m}$ in diameter $(10,000 \mathrm{X})$ 




Figure 15. Type I cement, hydrated at $0.5 \mathrm{~W} / \mathrm{C}$. Specimen aged 1 day. It exhibits a massive texture by this age. The surface is also cut by several large cracks (500X)

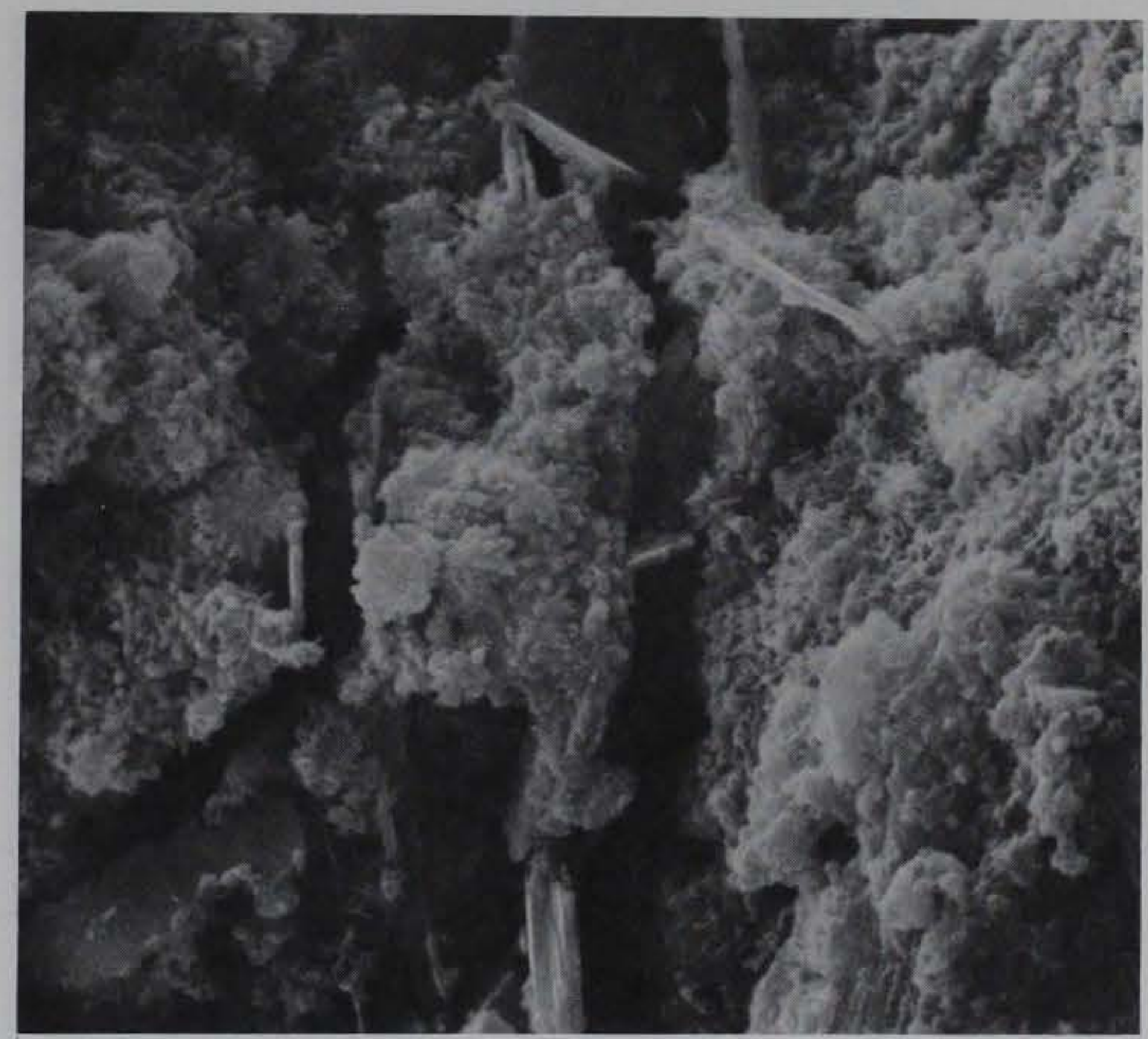

Figure 16. Type I cement, hydrated at $0.5 \mathrm{~W} / \mathrm{C}$. Specimen aged 1 day. The area shown is in the center of Figure 15. Much of the surface is coated by small crystals of calcium silicate hydrate. The platy crystals in the cracks indicate that the cracks formed during hydration rather than during specimen preparation. They may be calcium hydroxide or monosulfoaluminate or both (5000X) 


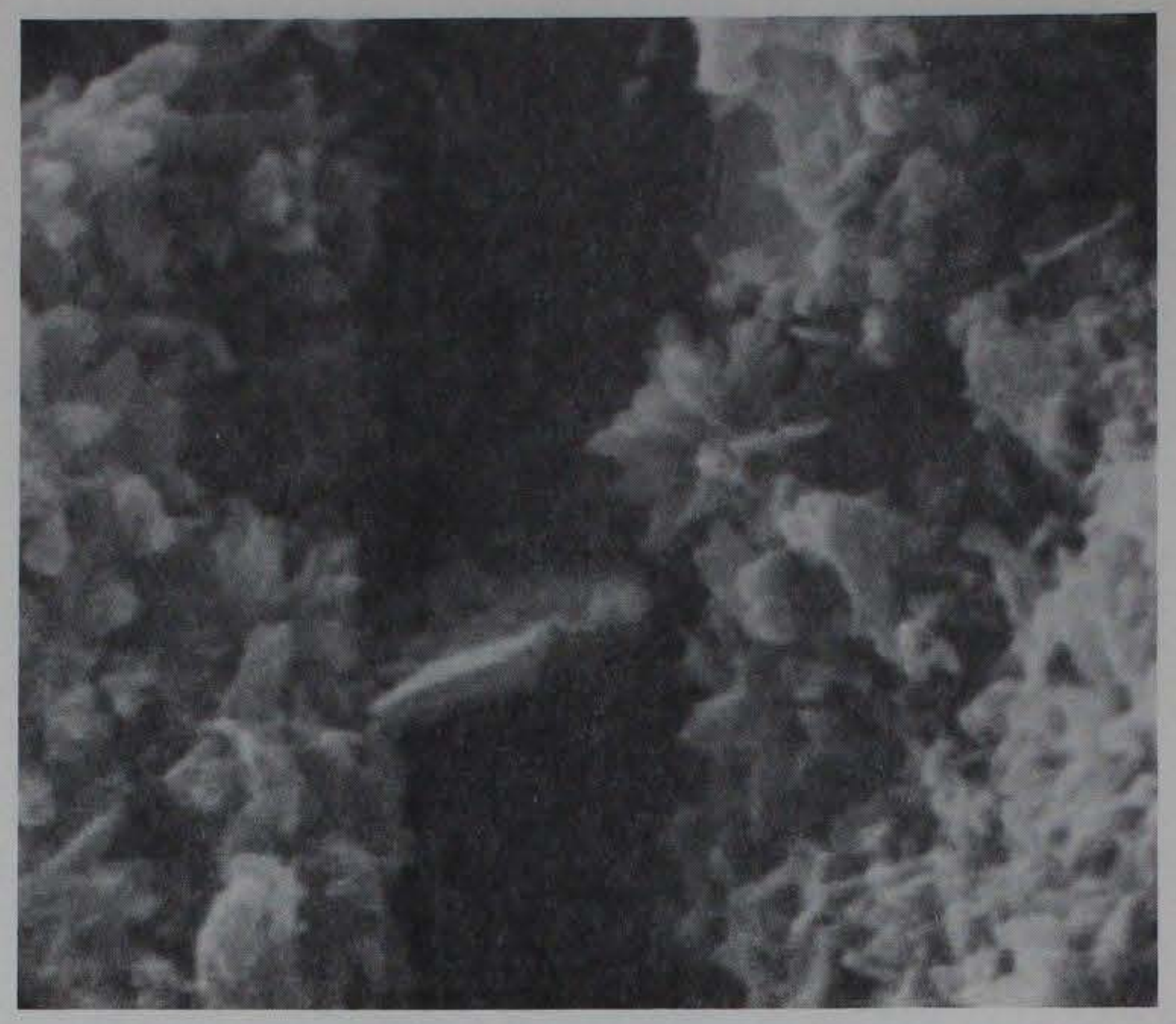

Figure 17. Type I cement, hydrated at $0.5 \mathrm{~W} / \mathrm{C}$. Specimen hydrated 1 day. This area is in the center of Figure 16 and shows the development of fibrous Type $I^{14}$ calcium silicate hydrate on the grain surfaces and platy material in the cracks. The flat crystal in the center of the micrograph is $0.15 \mu \mathrm{m}$ thick $(20,000 \mathrm{X})$ 


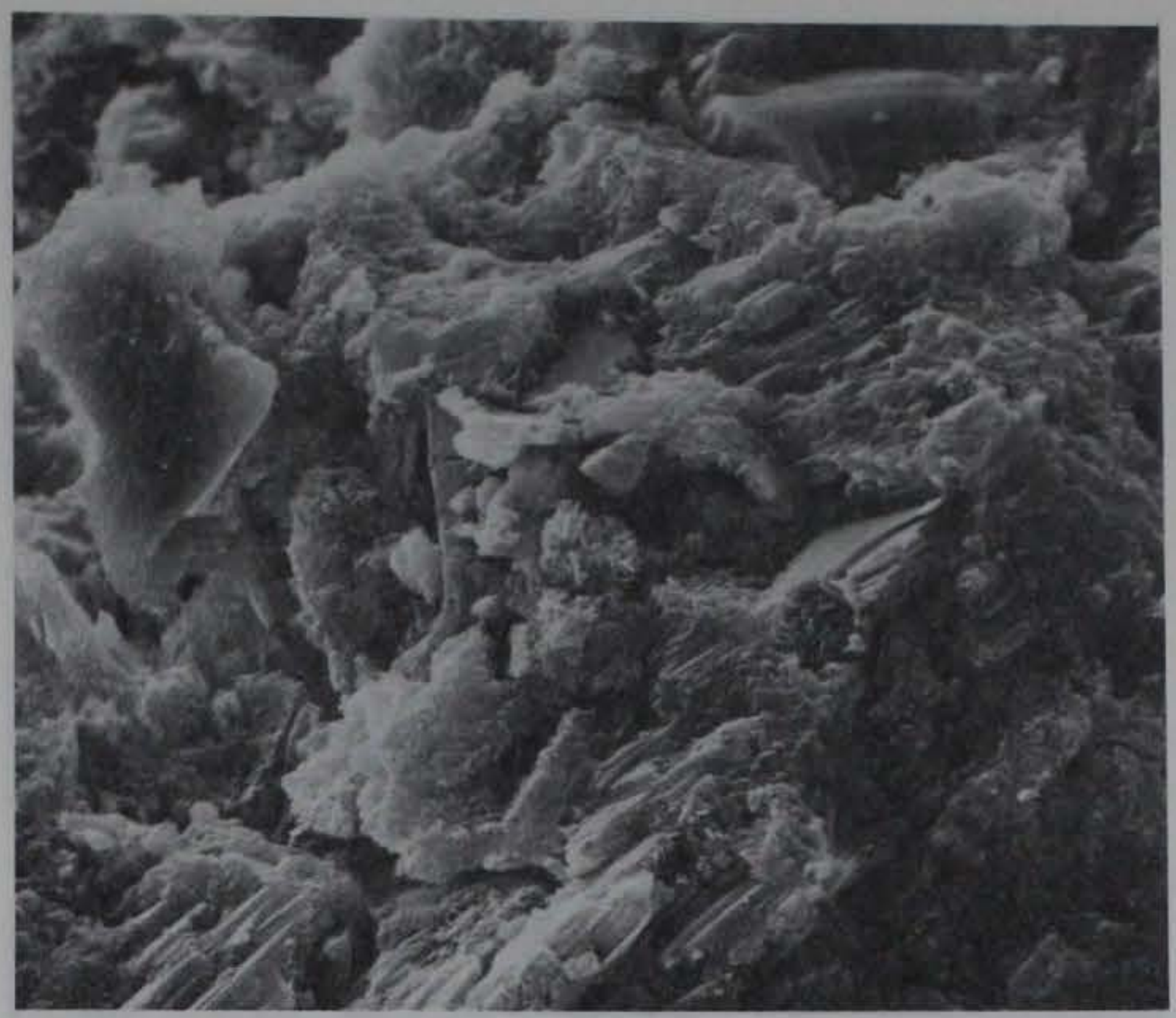

Figure 18. Type I cement, hydrated at $0.5 \mathrm{~W} / \mathrm{C}$. Specimen aged 3 days. In this specimen the more massive calcium hydroxide has developed to fill most of the pore space and engulf the finer hydration products (2000x)



Figure 19. Type I cement, hydrated at $0.5 \mathrm{~W} / \mathrm{C}$. Specimen aged 3 days. Shown is a small cluster of hydration products from the center of Figure 18 being engulfed by calcium hydroxide. The small hexagonal platelets may be a hexagonal tetracalcium aluminate hydrate such as tetracalcium aluminate monosulfate hydrate which has formed at the expense of ettringite. The platelets range from 0.20 to $0.25 \mu \mathrm{m}$ in diameter $(10,000 \mathrm{x})$ 


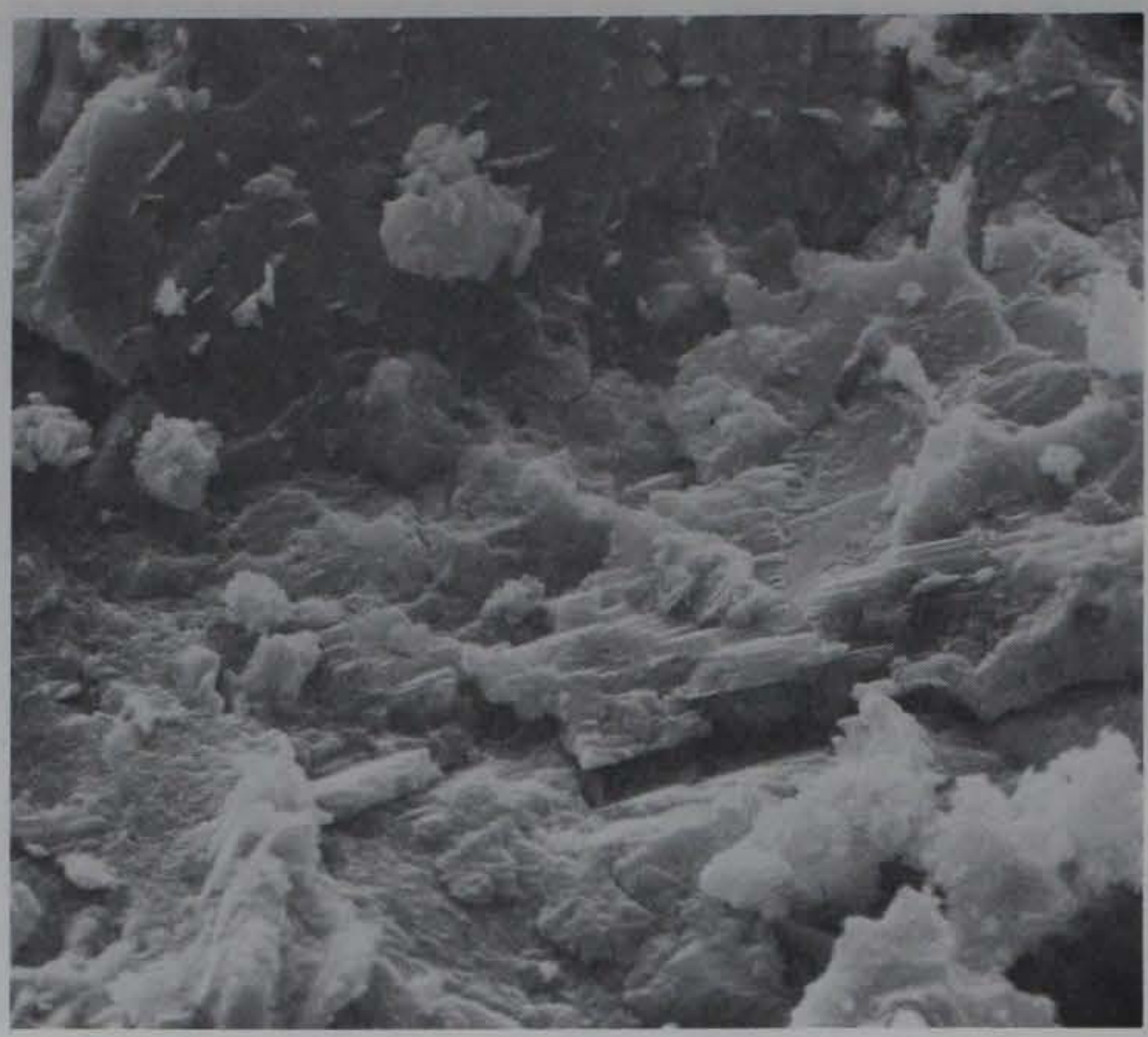

Figure 20. Type I cement, hydrated at $0.5 \mathrm{~W} / \mathrm{C}$. Specimen aged 7 days. The massive texture shown was typical of the specimen. The calcium hydroxide had engulfed most of the other hydration products. The small crack in the center of this figure is $0.2 \mu \mathrm{m}$ wide. It is believed that the smaller particles are equant Type III calcium silicate hydrate ${ }^{14}$ (2000X) 


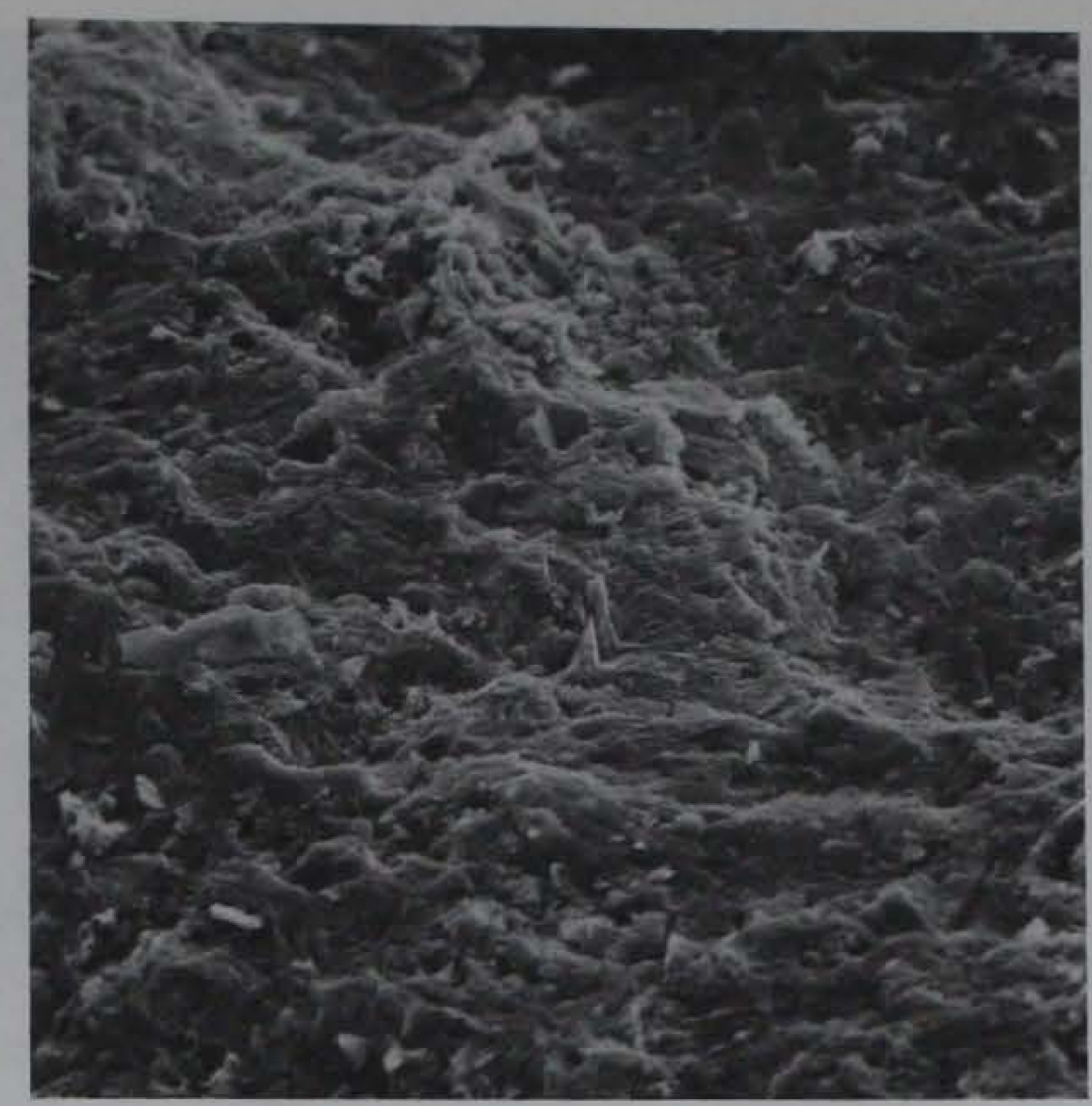

Figure 21. Type I cement, hydrated at $0.5 \mathrm{~W} / \mathrm{C}$. Specimen aged 28 days. Calcium hydroxide had filled most of the pore space at this age (550X)



Figure 22. Type I cement, hydrated at $0.5 \mathrm{~W} / \mathrm{C}$. Specimen aged 28 days. Enlarged view of center of Figure 21. In the left center is an area of calcium silicate hydrate that has been engulfed by calcium hydroxide

(2200X) 


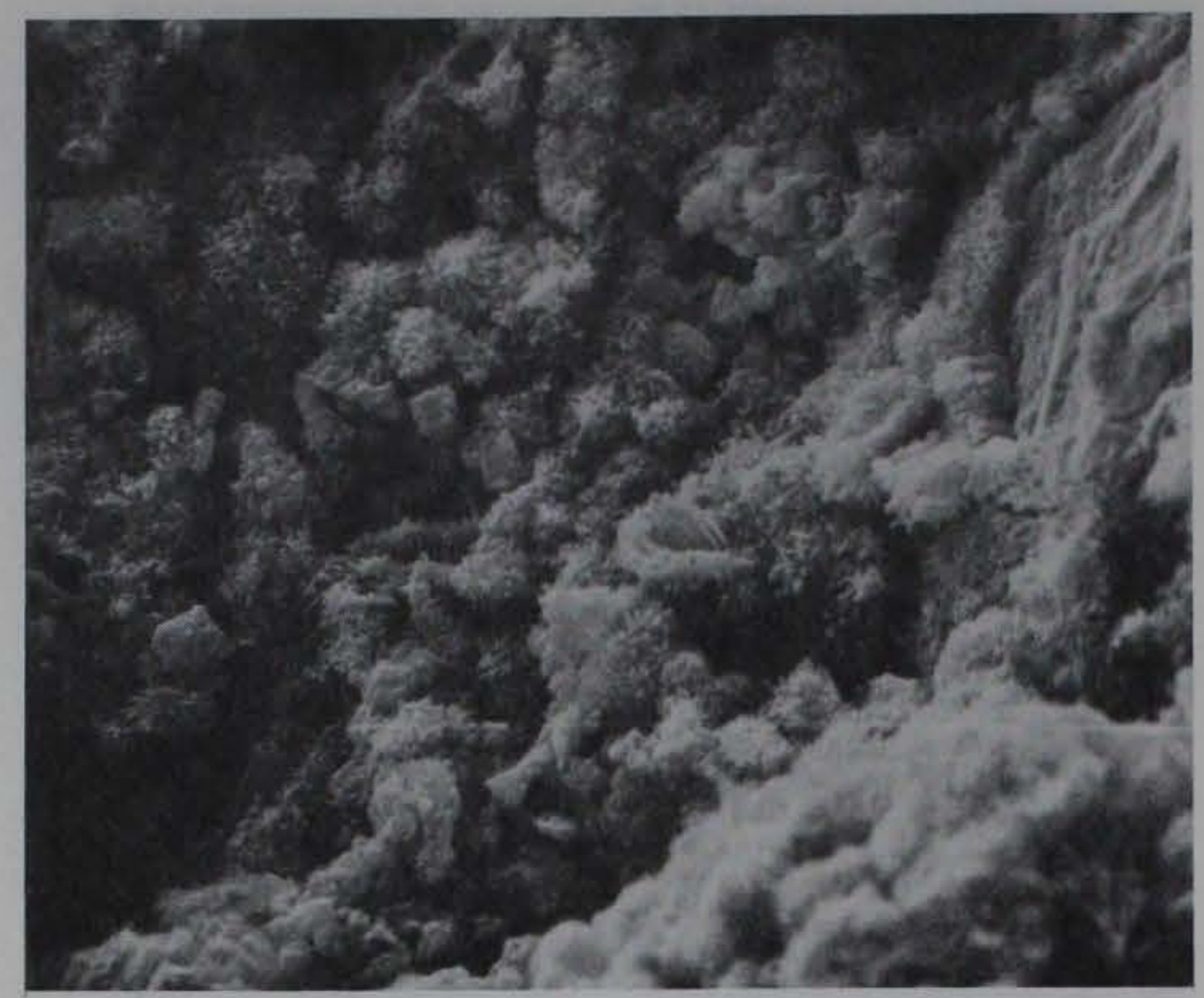

Figure 23. Type V cement, hydrated at $0.5 \mathrm{~W} / \mathrm{C}$. Specimen aged 1 day. Area shows development of calcium silicate hydrate and some ettringite crystals on the surface of the grain forming a porous interlocked coating (2000X)

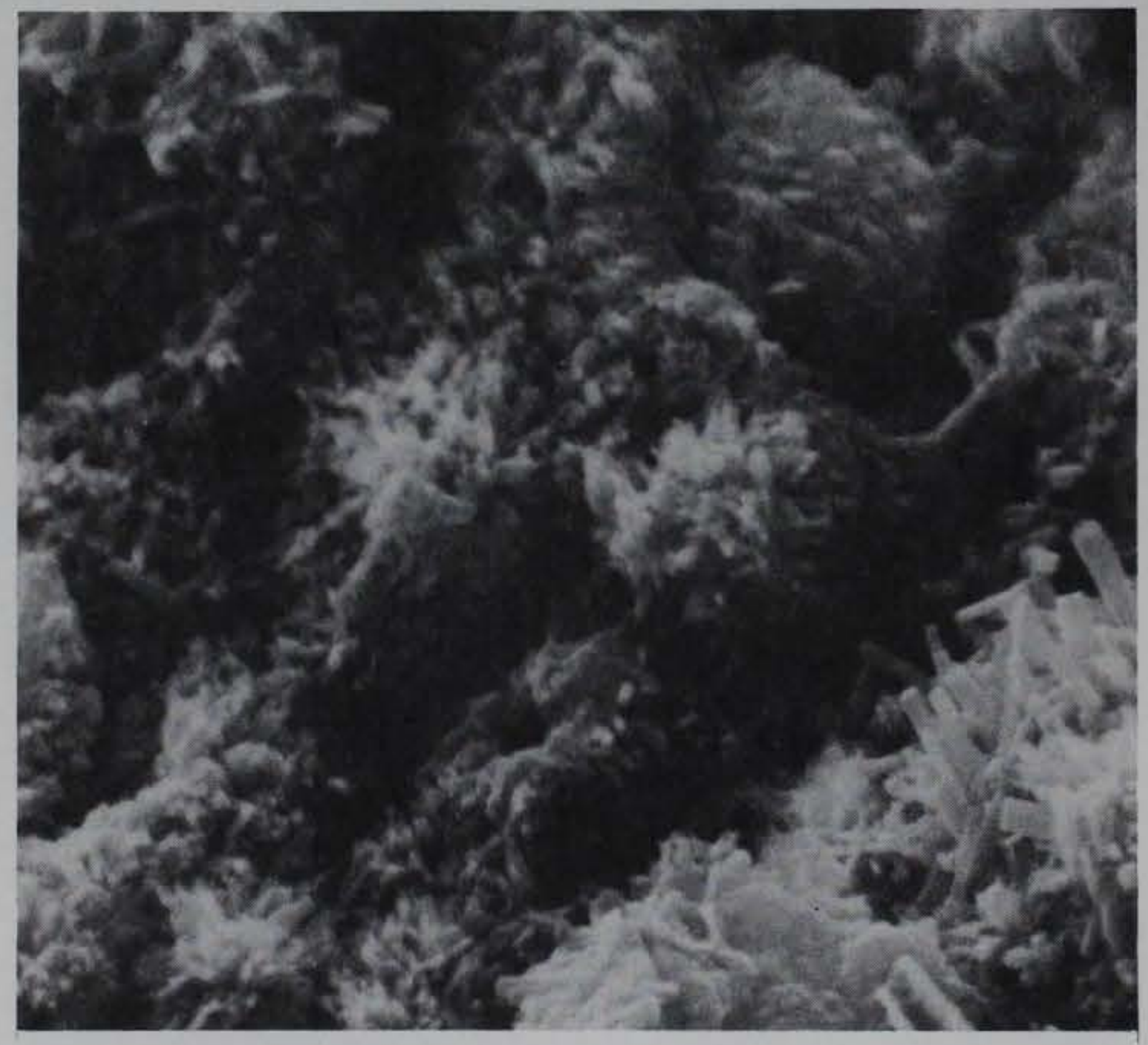

Figure 24. Type V cement, hydrated at $0.5 \mathrm{~W} / \mathrm{C}$. Specimen aged 1 day. Center of Figure 23 showing calcium silicate hydrate clusters in the center and ettringite in the lower right and upper left. In the upper right part of the calcium silicate hydrate cover has been broken off to expose a core of slightly hydrated cement which does not appear to be attached to the hydrated layer around it. 


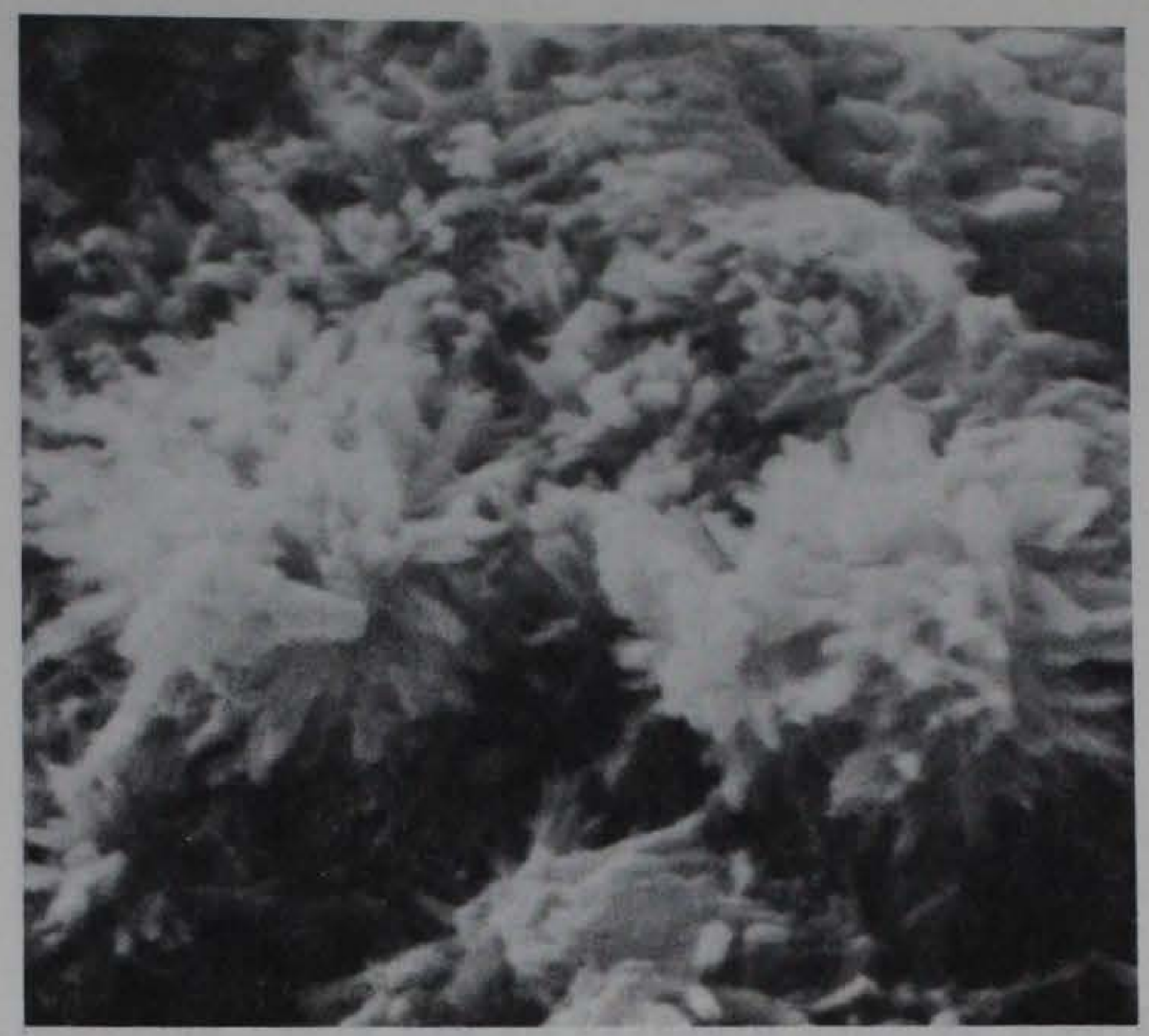

Figure 25. Type V cement, hydrated at $0.5 \mathrm{~W} / \mathrm{C}$. Specimen aged 1 day. Center of Figure 24 shows interlocked clusters of fibrous Type $I^{14}$ calcium silicate hydrate. The cluster on the right is $2 \mu \mathrm{m}$ in diameter $(20,000 x)$ 


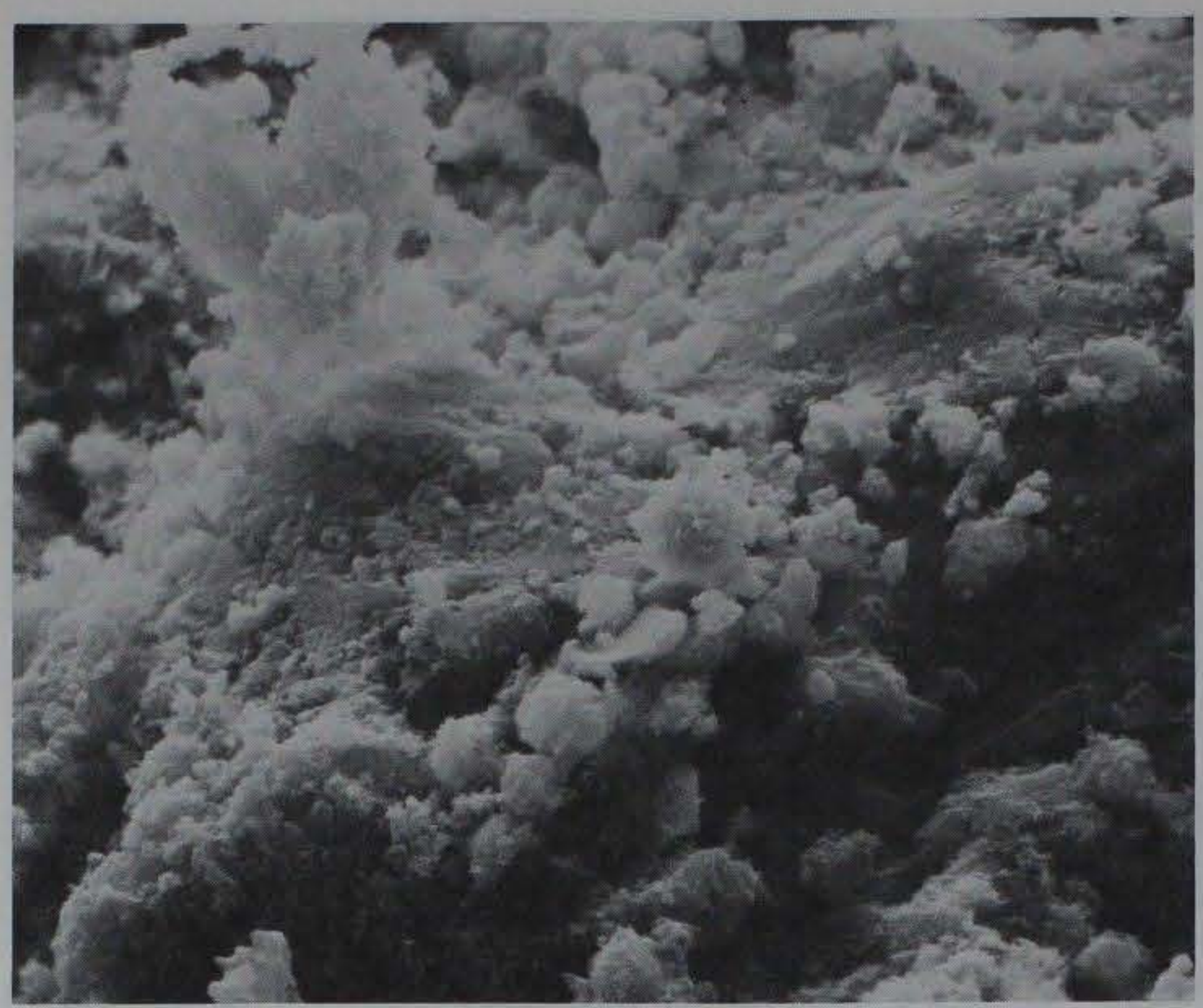

Figure 26. Type $\mathrm{V}$ cement, hydrated at $0.5 \mathrm{~W} / \mathrm{C}$. Specimen aged 3 days. The bulk of this specimen had a massive amorphous texture as shown here (2000X)

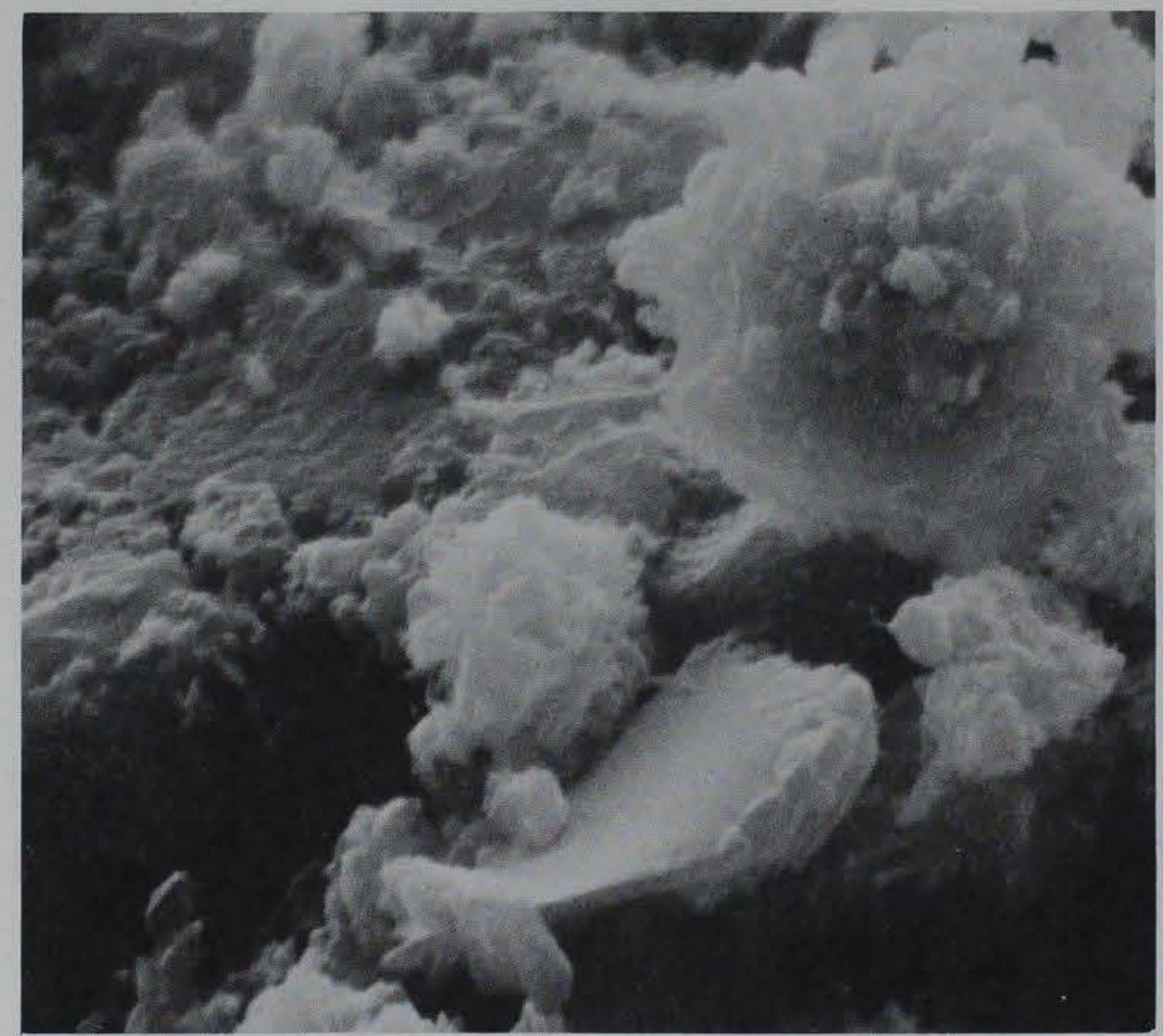

Figure 27. Type V cement, hydrated at $0.5 \mathrm{~W} / \mathrm{C}$. Specimen aged 3 days. Center part of Figure 26. In a few areas there were discrete clusters of calcium silicate hydrate associated with more massive calcium hydroxide. The calcium silicate hydrate is believed to be the equant grain Type $\operatorname{III}^{14}(10,000 \mathrm{X})$ 


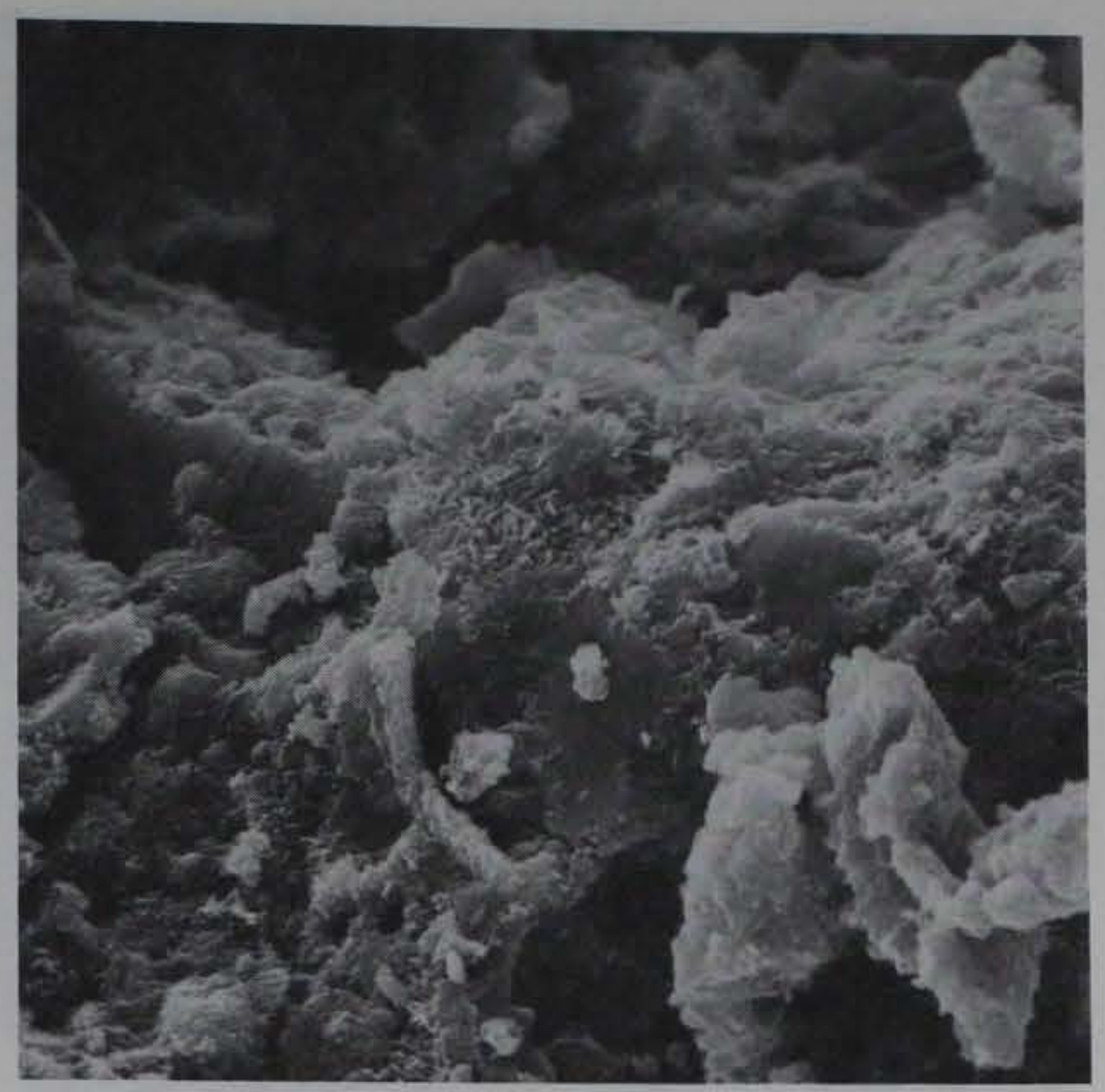

Figure 28. Type $\mathrm{V}$ cement, hydrated at $0.5 \mathrm{~W} / \mathrm{C}$. Specimen aged 7 days. Generally, this specimen was similar in texture to the 3-day-old specimen (Figure 26). Most of the calcium silicate hydrate and ettringite had been engulfed by calcium hydroxide (2000x)

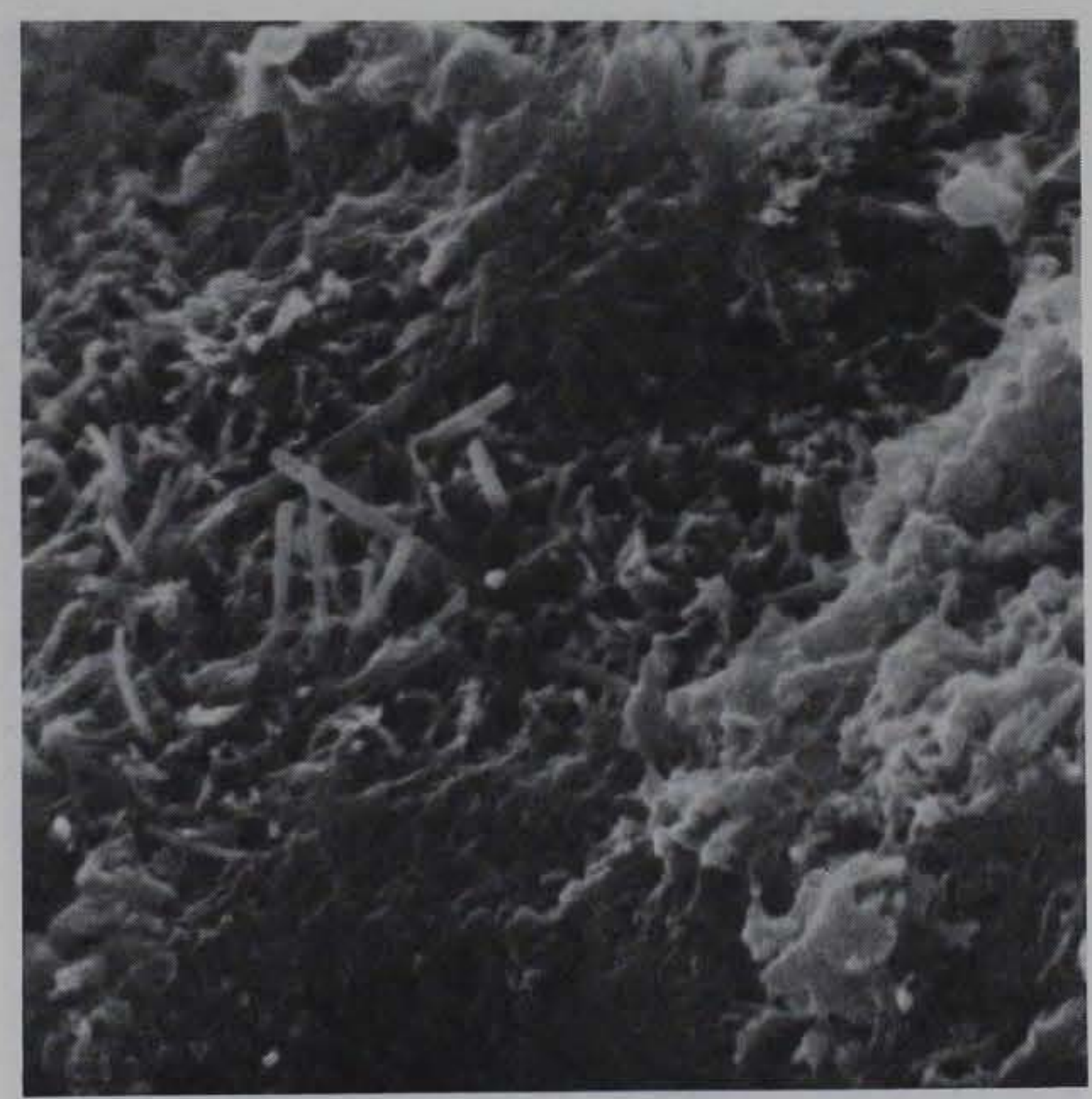

Figure 29. Type V cement, hydrated at $0.5 \mathrm{~W} / \mathrm{C}$. Specimen aged 7 days. Center of Figure 28 showing ettringite rods and partially engulfed calcium silicate hydrate clusters $(10,000 \mathrm{x})$ 


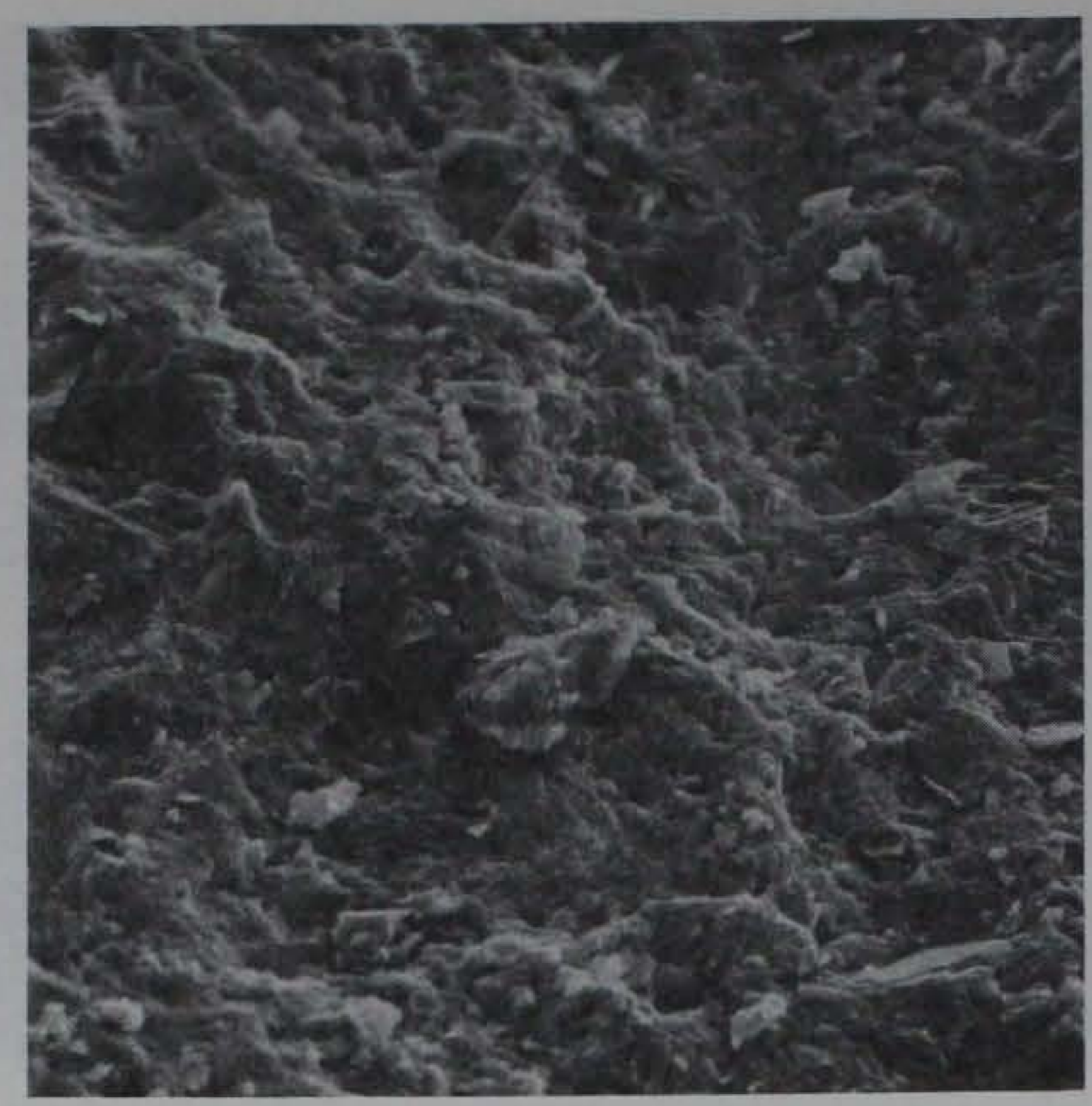

Figure 30. Type V cement, hydrated at $0.5 \mathrm{~W} / \mathrm{C}$. Specimen aged 28 days. At this age most of the specimen was massive and amorphous (500X)

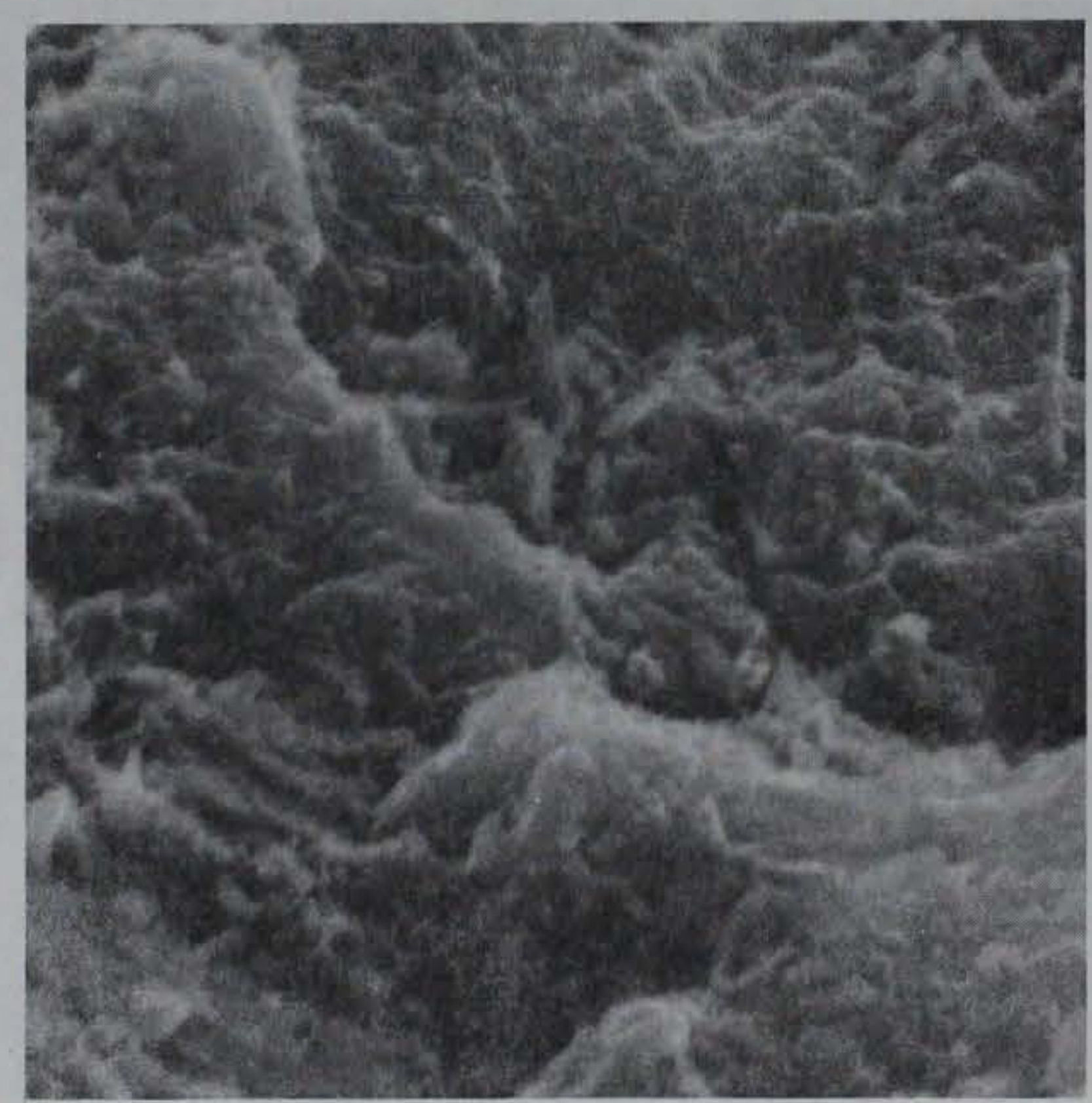

Figure 31. Type V cement, hydrated at $0.5 \mathrm{~W} / \mathrm{C}$. Specimen aged 28 days. Center of Figure 30 showing rods of ettringite (?) engulfed by calcium hydroxide $(10,000 \mathrm{x})$ 




Figure 32. Type $\mathrm{K}$ cement, hydrated at $0.5 \mathrm{~W} / \mathrm{C}$. Specimen aged 3 days. Specimen showed very little development of hydration product at this age $(2000 \mathrm{x})$

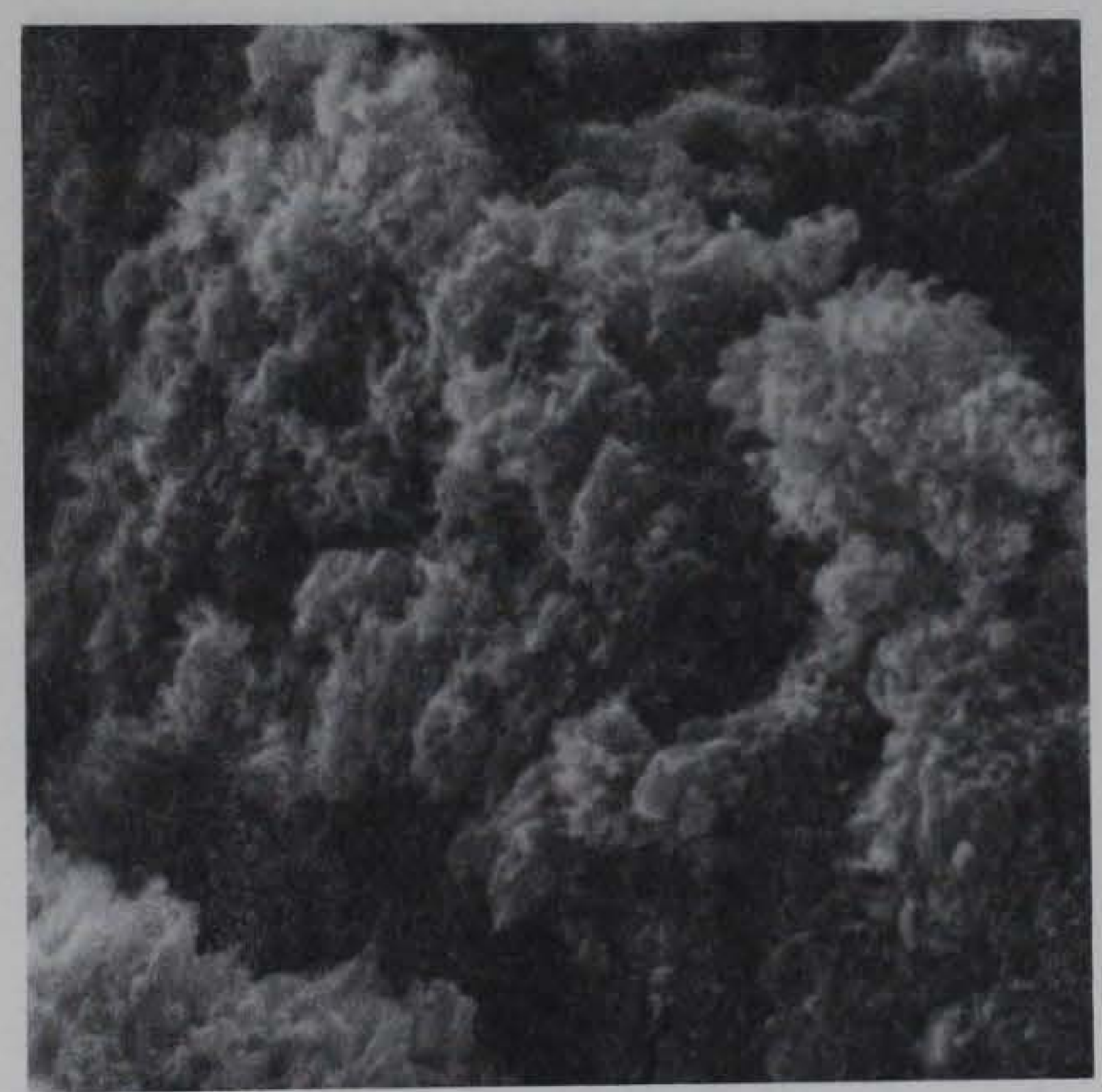

Figure 33. Type $\mathrm{K}$ cement, hydrated at $0.5 \mathrm{~W} / \mathrm{C}$. Specimen aged 3 days. Center of Figure 32 showing limited development of hydration products $(10,000 x)$ 


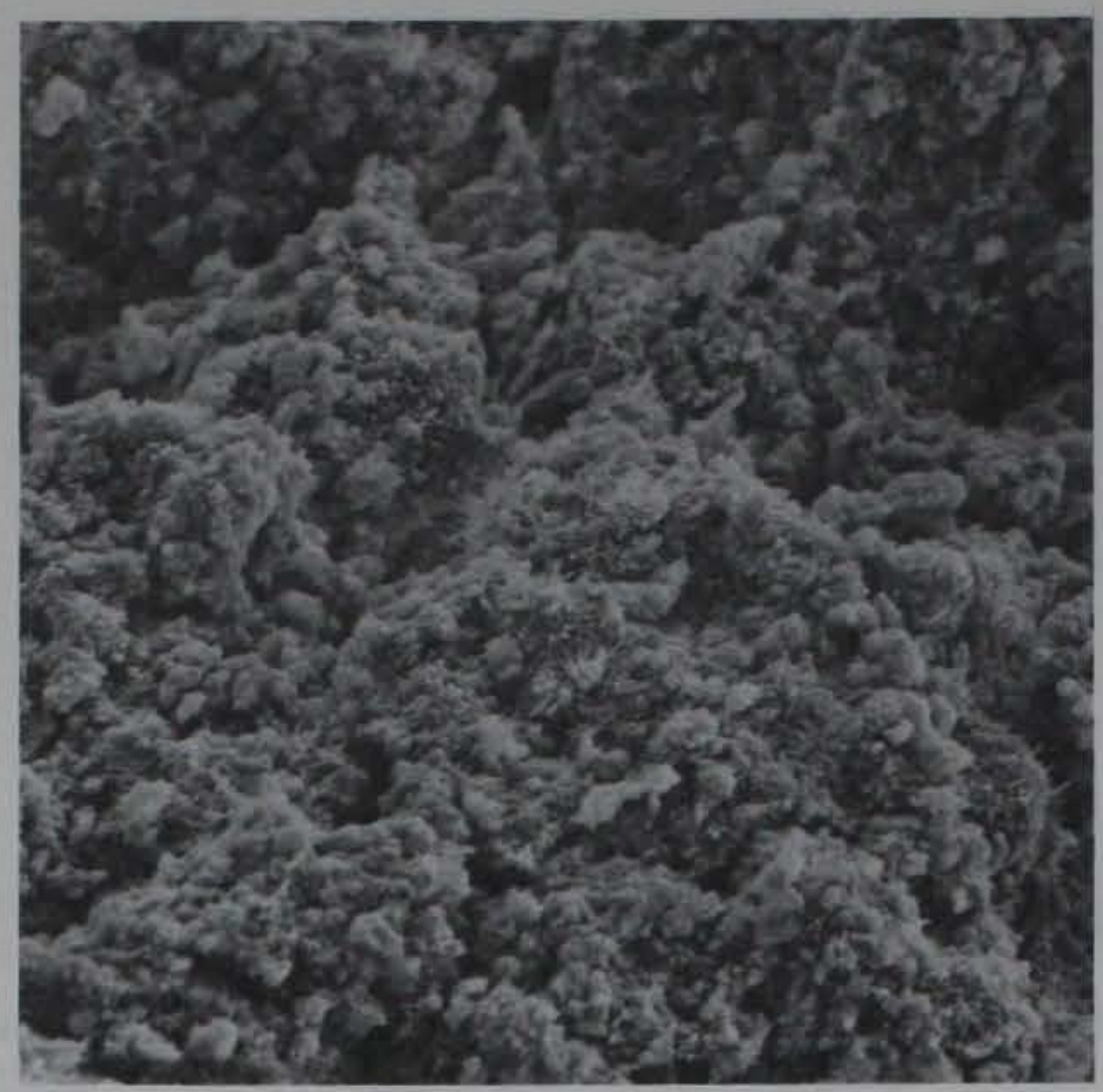

Figure 34. Type $\mathrm{K}$ cement, hydrated at $0.5 \mathrm{~W} / \mathrm{C}$. Specimen aged 28 days. Specimen showed little change in available pore space but did show considerable development of ettringite (500X)

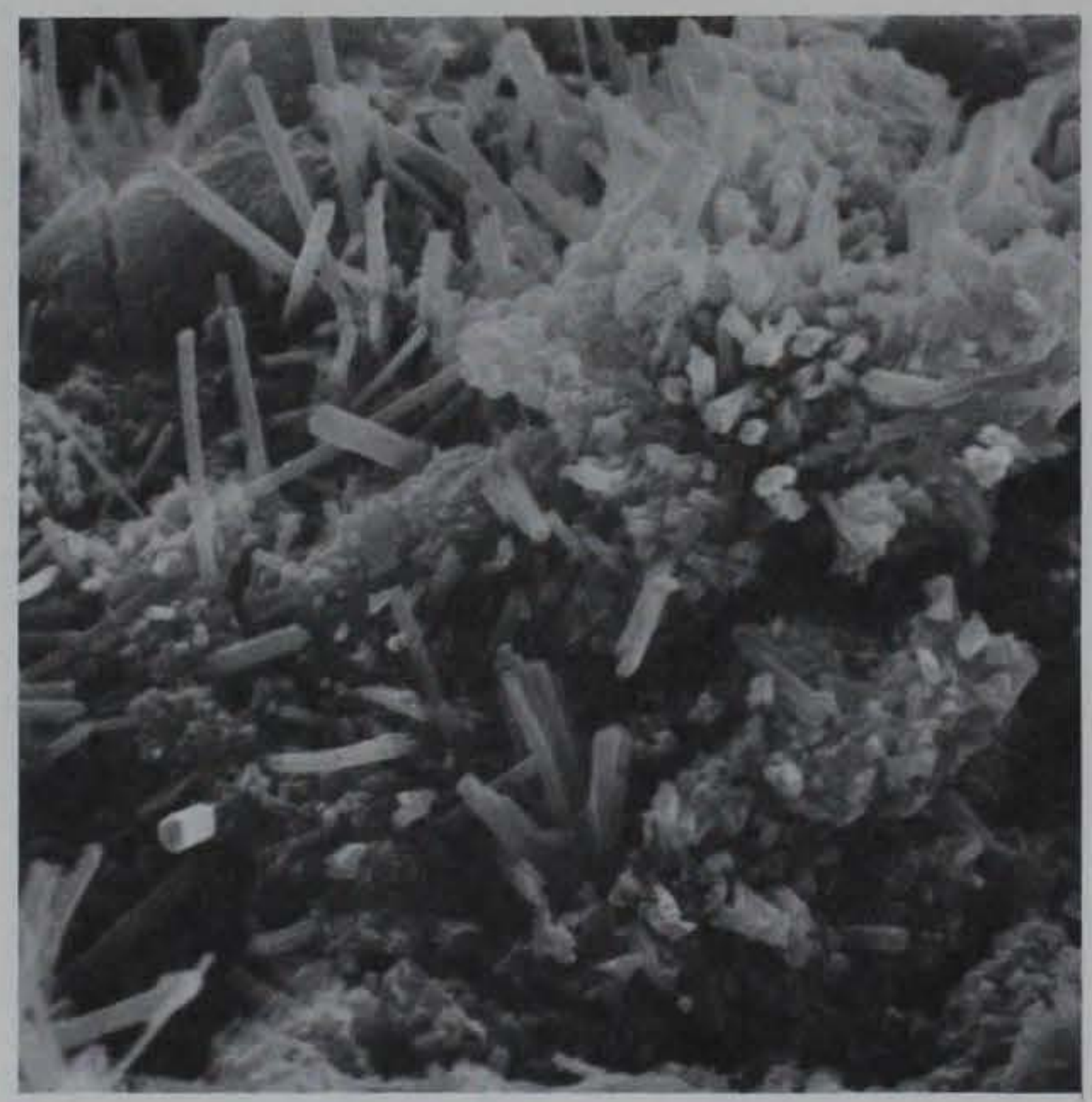

Figure 35. Type $\mathrm{K}$ cement, hydrated at $0.5 \mathrm{~W} / \mathrm{C}$. Specimen aged 28 days. Center of Figure 34. It shows development of ettringite and a considerable amount of cracking (5000X) 




Figure 36. Type $\mathrm{K}$ cement, hydrated at $0.5 \mathrm{~W} / \mathrm{C}$. Specimen aged 28 days. Upper center part of Figure 35 shows growth of ettringite both parallel and normal to grain surface $(20,000 \mathrm{x})$ 
Table 1

Analysis of Alite Clinker

\begin{tabular}{|c|c|}
\hline & $\begin{array}{c}\text { Mass, } \\
\% \\
\end{array}$ \\
\hline $\mathrm{CaO}$ & 70.7 \\
\hline $\mathrm{SiO}_{2}$ & 24.6 \\
\hline $\mathrm{Al}_{2} \mathrm{O}_{3}$ & 0.8 \\
\hline $\mathrm{Fe}_{2} \mathrm{O}_{3}$ & 0.8 \\
\hline $\mathrm{MgO}$ & 2.0 \\
\hline $\mathrm{SO}_{3}$ & 0.0 \\
\hline Loss on Ignition & 0.9 \\
\hline Alkalies - Total as $\mathrm{Na}_{2} \mathrm{O}$ & 0.00 \\
\hline Insoluble Residue & 0.18 \\
\hline Total & 99.98 \\
\hline Calculated Compounds & $\%$ \\
\hline $\mathrm{C}_{3} \mathrm{~S}$ & 94.3 \\
\hline $\mathrm{C}_{2} \mathrm{~S}$ & 0.0 \\
\hline $\mathrm{C}_{3} \mathrm{~A}$ & 0.8 \\
\hline $\mathrm{C}_{4} \mathrm{AF}$ & 2.4 \\
\hline Tota1 & 97.5 \\
\hline
\end{tabular}


Table 2

Chemical Analysis and Physical Tests of a Type I Cement



* Average of four determinations.

$* *$ Single determination. 


\section{Table 3}

Chemical Analysis and Physical Tests of a Type V Cement

\section{Chemical Data}

\section{$\mathrm{CaO}$}

$\mathrm{SiO}_{2}$

$\mathrm{Al}_{2} \mathrm{O}_{3}$

$\mathrm{Fe}_{2} \mathrm{O}_{3}$

$\mathrm{MgO}$

$\mathrm{SO}_{3}$

Loss on Ignition

Alkalies - Total as $\mathrm{Na}_{2} \mathrm{O}$

$\mathrm{Na}_{2} \mathrm{O}$

$\mathrm{K}_{2} \mathrm{O}$

Insoluble Residue

Calculated Compounds

$\mathrm{C}_{3} \mathrm{~S}$

$\mathrm{C}_{2} \mathrm{~S}$

$\mathrm{C}_{3} \mathrm{~A}$

$\mathrm{C}_{4} \mathrm{AF}$

Physical Data

Surface Area, $\mathrm{cm}^{2} / \mathrm{g}$ (A.P.)

Air Content

Compressive Strength, psi**

7 day

28 day

Autoclave Expansiont

Initial Set, hr:min

Final Set, hr:min

\section{Mass, \%*}

$65.3(65.3-65.4)$

$21.8(21.6-22.0)$

$3.2(3.2-3.3)$

$4.5(4.5-4.6)$

$2.0(1.9-2.1)$

1.9

$0.8(0.7-0.8)$

$0.43(0.42-0.45)$

$0.28 \quad(0.28-0.29)$

$0.23(0.21-0.24)$

$0.14(0.09-0.23)$

$66.9(65.3-68.1)$

$12.0(10.6-13.8)$

$0.9(0.7-1.1)$

$13.8(13.7-14.0)$

3360 (3305-3420)

$7.5(7.2-7.9)$

$4000(3710-4220)$

$5420(5330-5620)$

$-0.02$

$3: 30 \quad(3: 25-3: 40)$

$6: 08(6: 05-6: 15)$

\footnotetext{
* Average of four determinations.

** $0.485 \mathrm{~W} / \mathrm{C}$.

$\uparrow$ Normal consistency was 0.242 .
} 
Table 4

Chemical Analysis and Tests of RC-644 (3), a Type K Cement

\section{Chemical Tests}

$\mathrm{CaO}$

$\mathrm{SiO}_{2}$

$\mathrm{Al}_{2} \mathrm{O}_{3}$

$\mathrm{Fe}_{2} \mathrm{O}_{3}$

$\mathrm{MgO}$

$\mathrm{SO}_{3}$

Loss on Ignition

Insoluble Residue

Total Alkalies as $\mathrm{Na}_{2} \mathrm{O}$

$\mathrm{Na}_{2} \mathrm{O}$

$\mathrm{K}_{2} \mathrm{O}$

Physical Tests

Heat of Hydration, cal/g

1 day

3 days

7 days

Surface Area, $\mathrm{cm}^{2} / \mathrm{g}$

Specific Gravity

\section{Mass, \%}

57.6

14.6

8.4

1.6

2.7

12.4

1.9

1.09

0.47

0.15

0.49

day

3 days

51

70

79

4240

3.04

Cube Strengths, psi*

\section{5}

$45 * *$

0.528

* The cubes were stripped at $24 \mathrm{hr}$ and placed in limewater. ** Specimens cracked. 
Table 5

Alite and Hydration Products at $\mathrm{W} / \mathrm{C}=0.5$

by X-Ray Diffraction

\begin{tabular}{|c|c|c|c|c|c|c|}
\hline \multirow[b]{2}{*}{ Constituents } & \multirow[b]{2}{*}{ Original } & \multicolumn{2}{|c|}{ At Ages } & \multicolumn{3}{|c|}{ in Days Shown } \\
\hline & & 1 & 3 & 7 & 28 & 56 \\
\hline Alite & Predominant & $\mathrm{x}$ & $\mathrm{x}$ & $\mathrm{X}$ & $\mathrm{x}$ & $\mathrm{x}$ \\
\hline Belite & Minor & $\mathrm{x}$ & $\mathrm{x}$ & -- & -- & -- \\
\hline $\mathrm{C}_{3} \mathrm{~A}$ & Minor & $\mathrm{x}$ & -- & -- & -- & -- \\
\hline $\mathrm{MgO}$ & Minor & $\mathrm{x}$ & $\mathrm{x}$ & $\mathrm{X}$ & $\mathrm{X}$ & -- \\
\hline Calcium hydroxide & & $\mathrm{x}$ & $\mathrm{x}$ & $\mathrm{x}$ & $\mathrm{X}$ & $\mathrm{X}$ \\
\hline C S H & & $?$ & $\mathrm{x}$ & $\mathrm{x}$ & $\mathrm{X}$ & $\mathrm{X}$ \\
\hline $\mathrm{C}_{4} \mathrm{AH}_{13}$ & & -- & -- & $?$ & ? & ? \\
\hline
\end{tabular}

Changes in Intensity of Strong Lines, in Chart Units

\begin{tabular}{lcccccccc}
\hline & $\mathrm{d}, \mathrm{A}^{*}$ & $\mathrm{I}=100$ & & & & & \\
\hline Alite & 1.76 & 61 & 51.5 & 35 & 30 & 20 & 14 \\
Alite and some Belite & 2.18 & 58.5 & 48 & 31.5 & 28 & 19 & 13 \\
Belite & 2.88 & 3.5 & -- & -- & -- & -- & -- \\
MgO & 2.10 & 13 & 8.5 & 7 & 6.5 & $\star *$ & -- \\
Calcium hydroxide & 4.92 & 12.0 & 57.5 & 65.5 & 73 & $\dagger$ & 70 \\
C S H & 2.85 & -- & 4.5 & 7 & 7.5 & 11 & 15
\end{tabular}

* Original intensities in the unhydrated material except for the calcium hydroxide and CSH intensities which were measured initially in the 1-day specimen.

$* *$ Read 7.5 ; probably one or more large crystals and consequent excess intensity.

+ Sample too short for valid intensities below 20 deg 2-theta. 
Table 6

Constituents of a Material that Hydrates to Form Ettringite and Hydration Products at W/C $=0.5$

\begin{tabular}{|c|c|c|c|c|c|}
\hline \multirow[b]{2}{*}{ Constituents* } & Starting & \multicolumn{4}{|c|}{ At Ages in Days Shown Below } \\
\hline & Material & 1 & 3 & 7 & 28 \\
\hline $\mathrm{C}_{4} \mathrm{~A}_{3} \overline{\mathrm{S}}$ & Major & Abundant & Intermediate & Intermediate & ND \\
\hline $\mathrm{CaSO}_{4}$ & Major & Abundant & Abundant & Abundant & Minor \\
\hline $\mathrm{CaO}$ & Minor & $--* *$ & -- & -- & -- \\
\hline MgO & Trace & -- & Trace? & -- & -- \\
\hline $\mathrm{CaSO}_{4} \cdot 2 \mathrm{H}_{2} \mathrm{O}$ (2 lines) & Minor & Intermediate & Intermediate & Intermediate & Abundant \\
\hline $\mathrm{CaSO}_{4} \cdot \frac{1}{2} \mathrm{H}_{2} \mathrm{O}$ (2 1ines) & Minor & -- & -- & -- & -- \\
\hline Calcite (1 line) & Trace & Trace & Trace & Trace & Trace \\
\hline Aragonite (2 lines) & Trace** & Trace** & Trace*** & Trace $* *$ & Trace** \\
\hline Calcium hydroxide (3 lines)) & Abundant & Intermediate & ND & ND & ND \\
\hline $\begin{array}{l}\text { Ettringite ( } 2 \text { lines in }) \\
\text { starting material) }\end{array}$ & Minor & Abundant & Major & Major & Major \\
\hline
\end{tabular}

Changes in Intensity of Strong Lines in Chart Units

\begin{tabular}{|c|c|c|c|c|c|c|}
\hline & $\mathrm{d}, \mathrm{A}$ & I & 1 & 3 & 7 & 28 \\
\hline $\mathrm{C}_{4} \mathrm{~A}_{3} \overline{\mathrm{S}}$ & 3.76 & Off Scale & 52 & 23 & 25 & -- \\
\hline $\mathrm{CaSO}_{4}$ & 2.84 & 63 & 43.5 & 42 & 43 & 20 \\
\hline $\mathrm{CaSO}_{4} \cdot 2 \mathrm{H}_{2} \mathrm{O}$ & 7.6 & 18 & 26 & 20 & 24 & 45 \\
\hline Ettringite & 5.63 & 16 & 61 & 71 & 79 & 80 \\
\hline
\end{tabular}

* The sample was received in April 1964 and stored in a plastic bottle with a screw top, from which several samples were withdrawn, leaving the bottle partly full. It is believed that the substances listed as alteration products represent reactions with moist air. The samples also contained alumina and some frequently encountered but unidentified impurities of ettringite.

** Masked by an ettringite line. 
Table 7

A Type I Cement and Its Hydration Products

at $\mathrm{W} / \mathrm{C}=0.5$

\begin{tabular}{|c|c|c|c|c|c|c|}
\hline \multirow{2}{*}{$\begin{array}{c}\text { Constituents, } \\
\text { Cement }\end{array}$} & \multirow{2}{*}{\multicolumn{2}{|c|}{$\begin{array}{c}\text { Original } \\
\text { Cement }\end{array}$}} & \multicolumn{4}{|c|}{$\begin{array}{c}\text { Constituents at Ages in } \\
\text { Days Shown }\end{array}$} \\
\hline & & & 1 & 3 & 7 & 28 \\
\hline Alite & \multicolumn{2}{|l|}{ Major } & $\mathrm{x}$ & $\mathrm{x}$ & $\mathrm{X}$ & $\mathrm{x}$ \\
\hline Belite & \multicolumn{2}{|c|}{ Intermediate } & $\mathrm{X}$ & $\mathrm{X}$ & Masked & Masked \\
\hline $\mathrm{C}_{3} \mathrm{~A}$ & \multicolumn{2}{|c|}{ Minor* } & $\mathrm{X}$ & $\mathrm{X}$ & Masked & Masked \\
\hline Aluminoferrite & \multicolumn{2}{|l|}{ Minor } & $\mathrm{X}$ & $\mathrm{X}$ & $\mathrm{X}$ & X \\
\hline $\mathrm{MgO}$ & \multicolumn{2}{|l|}{ Trace } & $\mathrm{X}$ & $\mathrm{X}$ & $\mathrm{X}$ & $\mathrm{x}$ \\
\hline Gypsum & \multicolumn{2}{|l|}{ Minor } & -- & -- & -- & -- \\
\hline \multicolumn{7}{|l|}{ Hydration Products } \\
\hline Ettringite & \multicolumn{2}{|c|}{$\mathrm{x}$} & $\mathrm{x}$ & $\mathrm{x}$ & $\mathrm{x}$ & $\mathrm{X}$ \\
\hline $\mathrm{C}_{4} \mathrm{ASS}_{12}$ & \multicolumn{2}{|c|}{--} & $\mathrm{X}$ & $\mathrm{X}$ & $\mathrm{X}$ & $\mathrm{X}$ \\
\hline $8.7 \mathrm{~A}$ to $7.6 \mathrm{~A}$ material $* *$ & \multicolumn{2}{|c|}{--} & $\mathrm{X}$ & $\mathrm{X}$ & $\mathrm{X}$ & $\mathrm{X}$ \\
\hline Calcium hydroxide & \multicolumn{2}{|c|}{--} & $\mathrm{X}$ & $\mathrm{X}$ & $\mathrm{X}$ & $\mathrm{X}$ \\
\hline Hydrogarnet & \multicolumn{2}{|c|}{--} & -- & $\mathrm{X}$ & $\mathrm{X}$ & $\mathrm{x}$ \\
\hline \multirow[t]{3}{*}{$\mathrm{CSH}+$} & \multicolumn{2}{|c|}{-} & -- & -- & $\mathrm{x}$ & $\mathrm{x}$ \\
\hline & \multicolumn{2}{|c|}{ Changes : } & \multicolumn{4}{|c|}{$\begin{array}{l}\text { Intensity of Strong Lines } \\
\text { in Chart Units }\end{array}$} \\
\hline & $\mathrm{d}, \mathrm{A}$ & I & 1 & 3 & 7 & 28 \\
\hline Alite & 1.76 & 40 & 32 & 13.5 & 13 & 5 \\
\hline Alite and Belite & 2.18 & 37.5 & 27.5 & 18 & 14 & 8 \\
\hline $\mathrm{C}_{3} \mathrm{~A}$ & 1.555 & 15.5 & 8 & $\begin{array}{r}\text { Maske } \\
h\end{array}$ & $\begin{array}{l}\text { d by cal } \\
\text { ydroxide }\end{array}$ & cium \\
\hline Aluminoferrite & 7.3 & 10.5 & 7.5 & 6 & 4 & 4 \\
\hline $\mathrm{MgO}$ & 2.10 & 11 & $+t$ & 11 & 9.5 & 9.5 \\
\hline Gypsum & 7.6 & 19 & -- & -- & -- & -- \\
\hline Ettringite & 9.7 & 7 & 12 & 3 & $2 *$ & $2 *$ \\
\hline $\mathrm{C}_{4} \mathrm{ASH}_{12}$ & 8.9 & -- & 23 & 25 & 26.5 & 28 \\
\hline Calcium hydroxide & 4.9 & -- & 42.5 & 46.5 & 46 & 47.5 \\
\hline $\mathrm{CSH}$ & 2.85 & -- & 5 & 5.5 & 6.5 & 10.5 \\
\hline
\end{tabular}

* One line remaining.

** A hump continuous with the 8.9-A line of $\mathrm{C}_{4} \mathrm{AS} \bar{S}_{12}$, containing several tetracalcium aluminate hydrates such as tetracalcium aluminate hydroxy-sulfate hydrate, tetracalcium aluminate-13-hydrate, tetracalcium aluminate hemicarbonate-12-hydrate, tetracalcium aluminate monocarbonate11-hydrate.

+ Recognized as an increase in background between 26 and 36 degrees two-theta, at a maximum near $3.06 \mathrm{~A}$.

t+ Excess intensity probably arising from one or more large crystals. 
Table 8

Type V Cement and Its Hydration Products

at $\mathrm{W} / \mathrm{C}=0.5$

\begin{tabular}{|c|c|c|c|c|c|c|}
\hline Constituents* & \multicolumn{2}{|c|}{$\begin{array}{c}\text { Original } \\
\text { Cement }\end{array}$} & $\frac{\text { At }}{1}$ & $\frac{\text { ges i }}{3}$ & $\frac{n \text { Days }}{\frac{7}{4}}$ & $\frac{\text { Shown }}{28}$ \\
\hline Alite & Major & & $\mathrm{x}$ & $\mathrm{x}$ & $\mathrm{x}$ & $\mathrm{x}$ \\
\hline Belite & Minor & & $\mathrm{x}$ & $\mathrm{x}$ & nd & nd \\
\hline Aluminoferrite & Inter & liate & $\mathrm{X}$ & $\mathrm{x}$ & $\mathrm{X}$ & $\mathrm{X}$ \\
\hline Gypsum & Minor & & -- & -- & -- & -- \\
\hline $\mathrm{CaSO}_{4} \cdot 0.5 \mathrm{H}_{2} \mathrm{O}$ & Minor & & -- & -- & -- & -- \\
\hline Ettringite & Trace & & $\mathrm{x}$ & $\mathrm{X}$ & $\mathrm{X}$ & $\mathrm{X}$ \\
\hline Calcite & Trace & & -- & -- & -- & -- \\
\hline $\mathrm{C}_{4} \mathrm{AH}_{13}$ (?) & & & -- & $\mathrm{X}$ & $\mathrm{X}$ & -- \\
\hline $\mathrm{C}_{4} \mathrm{AC}_{0} .5 \mathrm{H}_{12}$ (?) & & & $\mathrm{X}$ & -- & -- & $\mathrm{X}$ \\
\hline $\mathrm{C}_{4} \mathrm{ACH}_{11}$ (?) & & & -- & -- & -- & $\mathrm{X}$ \\
\hline Calcium Hydroxide & & & $\mathrm{x}$ & $\mathrm{x}$ & $\mathrm{x}$ & $\mathrm{x}$ \\
\hline \multirow[t]{3}{*}{$\mathrm{CSH}$} & & & $\mathrm{X}$ & $\mathrm{x}$ & $\mathrm{x}$ & $\mathrm{X}$ \\
\hline & \multicolumn{6}{|c|}{$\begin{array}{c}\text { Changes in Intensity of Strong } \\
\text { Lines in Chart Units }\end{array}$} \\
\hline & $\mathrm{d}, \mathrm{A}$ & $\mathrm{I}$ & & & & \\
\hline Alite & 1.76 & 37 & 30 & 19.5 & 8 & 4 \\
\hline Alite and Belite & 2.18 & 37.5 & 26 & 18.5 & 10.5 & 8.5 \\
\hline Aluminoferrite & 7.3 & 13 & 10 & 8.5 & 8.5 & 7 \\
\hline Ettringite & 9.7 & -- & 12.5 & 12.5 & 12 & 11 \\
\hline Gypsum & 7.6 & 13.5 & - & - & - & - \\
\hline Calcium hydroxide & 4.9 & -- & 41 & 38 & 54 & 44 \\
\hline $\mathrm{CSH}$ & 2.85 & -- & 6 & 7 & 7 & 10 \\
\hline
\end{tabular}

* $\mathrm{C}_{3} \mathrm{~A}$ was not detected. 
Table 9

A Type K Self-Stressing Cement and Its Hydration Products at $\mathrm{W} / \mathrm{C}=0.5$

\begin{tabular}{|c|c|c|c|c|c|c|}
\hline \multirow{2}{*}{ Constituents } & \multirow{2}{*}{\multicolumn{2}{|c|}{ Original Cement* }} & \multicolumn{4}{|c|}{ At Ages in Days Shown } \\
\hline & & & 1 & 3 & 7 & 28 \\
\hline Aluminoferrite & \multicolumn{2}{|l|}{ Minor } & Minor & Minor & Minor & Tracet \\
\hline $\mathrm{CaSO}_{4} \cdot 0.5 \mathrm{H}_{2} \mathrm{O}$ & \multicolumn{2}{|l|}{ Minor } & Not detected & & ND & ND \\
\hline $\mathrm{C}_{4} \mathrm{~A}_{3} \frac{4}{\mathrm{~S}}$ & \multicolumn{2}{|c|}{ Commont } & Common & Common & Minor & Trace \\
\hline $\mathrm{CaSO}_{4}$ & \multicolumn{2}{|c|}{ Common } & Common & $?$ & $?$ & $?$ \\
\hline Belite & \multicolumn{2}{|c|}{ Commont } & Common & Minor & Minor & Minor \\
\hline $\mathrm{MgO}$ & \multicolumn{2}{|c|}{ Tracet } & Trace & Trace & Trace & Trace \\
\hline Alite & \multicolumn{2}{|c|}{ Minor } & Trace & Trace & Trace & Trace \\
\hline $\mathrm{CaO}$ & \multicolumn{2}{|c|}{ Minort } & Minor & ? Masked & Masked & Masked \\
\hline Calcium hydroxide & \multicolumn{2}{|c|}{ Minor } & Minor & Minort & Common- & Minor \\
\hline Ettringite & \multicolumn{2}{|l|}{ Trace } & Common & Common & Abundant & Abundant \\
\hline \multirow[t]{3}{*}{$\mathrm{CaSO}_{4} \cdot 2 \mathrm{H}_{2} \mathrm{O}$} & Not $d e$ & & Common & Minor & ND & Trace \\
\hline & \multicolumn{2}{|c|}{ Initial } & 1 & 3 & 7 & 28 \\
\hline & d, A & $I$ & & & & \\
\hline Aluminoferrite & 7.3 & 13 & $10 ?$ & 12 & 9 & 6 \\
\hline $\mathrm{CaSO}_{4} \cdot 0.5 \mathrm{H}_{2} \mathrm{O}$ & 6.0 & 28 & nd & nd & nd & nd \\
\hline $\mathrm{C}_{4} \mathrm{~A}_{3} \frac{4}{\mathrm{~S}}$ & 3.75 & 42 & 25 & 20 & 21 & 3.5 \\
\hline $\mathrm{CaSO}_{4}$ & 2.84 & 30 & nd & 10 & 12.5 & 11 \\
\hline Belite & 2.88 & 21 & 19 & 12 & 11 & 11 \\
\hline $\mathrm{MgO}$ & 2.10 & 23 & 17 & 13 & 14 & 14 \\
\hline Alite & 1.76 & 33 & 5 & 7 & 10 & 8 \\
\hline $\mathrm{CaO}$ & 2.40 & 44 & $23 * *$ & $11 * *$ & $13 * *$ & $12 * *$ \\
\hline Calcium hydroxide & 4.9 & 38 & 38 & 46 & 50 & 42 \\
\hline Ettringite & 5.6 & -- & 38 & 48 & 55 & 56 \\
\hline $\mathrm{CaSO}_{4} \cdot 2 \mathrm{H}_{2} \mathrm{O}$ & 7.6 & nd & 33 & 18 & nd & 5 \\
\hline
\end{tabular}

* Possible traces of $\mathrm{C}_{3} \mathrm{AH}_{6}$ and of quartz were observed in the cement.

** $\mathrm{CaO}$ and ettringite. 